\title{
Effects of cumulus parameterization and land-surface hydrology schemes on Tibetan Plateau climate simulation during the wet season: insights from the RegCM4 model
}

\author{
Xuejia Wang ${ }^{1,2} \cdot$ Deliang Chen ${ }^{2}$ (D) Guojin Pang ${ }^{2,3} \cdot$ Samy A. Anwar ${ }^{4} \cdot$ Tinghai Ou $^{2} \cdot$ Meixue Yang $^{1}$
}

Received: 16 November 2020 / Accepted: 19 April 2021 / Published online: 5 May 2021

(c) The Author(s) 2021

\begin{abstract}
Dynamical downscaling generally performs poorly on the Tibetan Plateau (TP), due to the region's complex topography and several aspects of model physics, especially convection and land surface processes. This study investigated the effects of the cumulus parameterization scheme (CPS) and land-surface hydrology scheme (LSHS) on TP climate simulation during the wet season using the RegCM4 regional climate model. To address these issues and seek an optimal simulation, we conducted four experiments at a $20 \mathrm{~km}$ resolution using various combinations of two CPSs (Grell and MIT-Emanuel), two LSHSs (the default TOPMODEL [TOP], and Variable Infiltration Capacity [VIC]). The simulations in terms of 2-m air temperature, precipitation (including large-scale precipitation [LSP] and convective precipitation $[\mathrm{CP}]$ ), surface energy-water balance, as well as atmospheric moisture flux transport and vertical motion were compared with surface and satellite-based observations as well as the ERA5 reanalysis dataset for the period 2006-2016. The results revealed that the model using the Grell and TOP schemes better reproduced air temperature but with a warm bias, part of which could be significantly decreased by the MIT scheme. All schemes simulated a reasonable spatial distribution of precipitation, with the best performance in the experiment using the MIT and VIC schemes. Excessive precipitation was produced by the Grell scheme, mainly due to overestimated LSP, while the MIT scheme largely reduced the overestimation, and the simulated contribution of CP to total precipitation was in close agreement with the ERA5 data. The RegCM4 model satisfactorily captured diurnal cycles of precipitation amount and frequency, although there remained some differences in phase and magnitude, which were mainly caused by the CPSs. Relative to the Grell scheme, the MIT scheme yielded a weaker surface heating by reducing net radiation fluxes and the Bowen ratio. Consequently, anomalous moisture flux transport was substantially reduced over the southeastern TP, leading to a decrease in precipitation. The VIC scheme could also help decrease the wet bias by reducing surface heating. Further analysis indicated that the high CP in the MIT simulations could be attributed to destabilization in the low and mid-troposphere, while the VIC scheme tended to inhibit shallow convection, thereby decreasing CP. This study's results also suggest that CPS interacts with LSHS to affect the simulated climate over the TP.
\end{abstract}

Keywords Climate simulation · Regional climate model $\cdot$ Tibetan Plateau $\cdot$ Parameterization scheme $\cdot$ Energy and water balance $\cdot$ Ground heating effect

Xuejia Wang

xjwang@1zb.ac.cn

Deliang Chen

deliang@gvc.gu.se

1 State Key Laboratory of Cryospheric Science, Northwest Institute of Eco-Environment and Resources, Chinese Academy of Sciences, Lanzhou, China
2 Reginal Climate Group, Department of Earth Sciences, University of Gothenburg, Gothenburg, Sweden

3 Faculty of Geomatics, Lanzhou Jiaotong University, Lanzhou, China

4 Egyptian Meteorological Authority, Qobry EL-Kobba, P.O. Box 11784, Cairo, Egypt 


\section{Introduction}

The Tibetan Plateau (TP), also known by scientists as the "Third Pole", is well recognized as exerting significant influence on regional and even global weather and climate systems through its thermodynamic and mechanical forcing (Duan et al. 2012; Wu et al. 2015). The TP is also referred to as the "Asian water tower" due to its extensively developed cryosphere and the fact that it is the source of several major Asian river systems, including the Yangtze River, Yellow River, Lancang-Mekong, and Ganges River, which provide substantial amounts of water to surrounding and downstream areas (Immerzeel et al. 2010). The TP has experienced significant warming over the past 50 years, at a rate of approximately $0.3-0.4^{\circ} \mathrm{C}$ per decade, twice the global temperature rise (Chen et al. 2015). Major climate-induced changes have occurred, such as shrinkage of cryospheric elements (glacier retreat, permafrost degradation, and snow cover decrease) (Yang et al. 2019) and intensification of the hydrological cycle (Yao et al. 2018). A recent study demonstrated that the TP, as the main body of the Asian water tower, is the most important and also the most vulnerable water tower component (Immerzeel et al. 2020). Therefore, an in-depth understanding of climate change in a sensitive and vulnerable region such as the TP is of great significance for maintaining the water tower and addressing other eco-environmental issues.

In general, coverage of the meteorological station network on the TP is poor, with most stations concentrated on the central and eastern TP, as well as low-elevation areas. This makes it difficult and speculative to comprehend the vital processes crucial to regional climate and

(a) Domain and topography

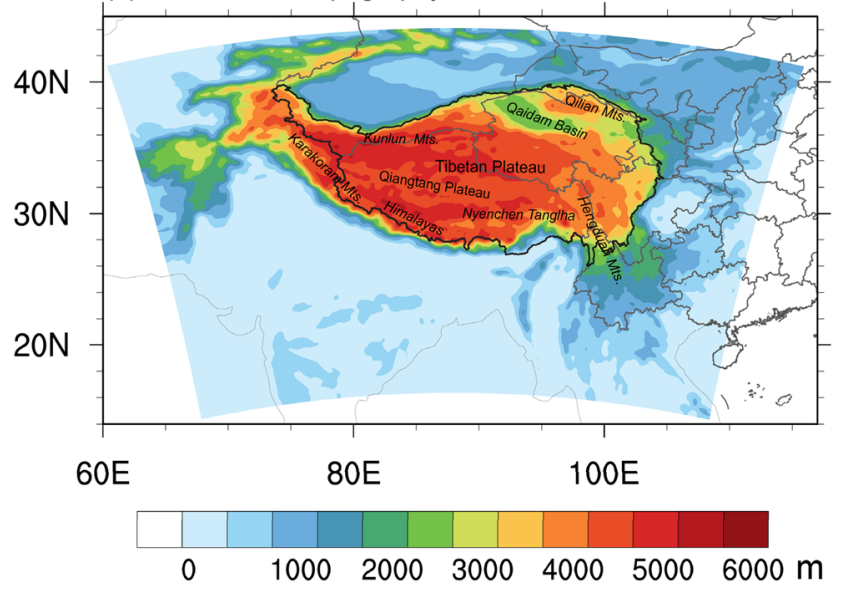

land-atmosphere interactions (Chen et al. 2015). Global reanalyses are then used to investigate processes that are crucial to regional climate over the TP (e.g., You et al. 2015; Zhang et al. 2017; Bao and Zhang 2019; Wang et al. 2020). However, the resolutions of commonly available reanalyses are too coarse to resolve many smaller-scale processes, such as atmospheric processes in mountainous topography and precipitation generation over the TP (Chen et al. 2016). Regional climate models (RCMs) are indispensable tools that dynamically downscale reanalyses or global climate models (GCMs) to reproduce the current climate and project future climate change with high spatial resolutions; they have been widely used to depict regionalscale details and resolve small-scale processes that GCMs with resolutions that are too coarse often fail to do (e.g., Leung et al. 2006; Gao et al. 2011; Wang et al. 2013, 2021; Saini et al. 2015; Giorgi et al. 2016; Gao and Chen 2017; Giorgi 2019; Gutowski et al. 2020; Ou et al. 2020). RCMs, however, have a number of uncertainties when simulating climate as a result of various model physical parameters, climate variability, and topographic complexity. These are particularly challenging over the TP, which is the highest and most extensive plateau on earth and features a high degree of surface heterogeneity. Numerous mountains, such as the Kunlun Mountains in the north, the Himalayas in the southern margin, the Karakoram Mountains in the west, and the Tanggula Mountains in the middle, are widespread on the TP. The altitude in the TP increases gradually from southeast to northwest (Fig. 1a), the topography varies greatly over small areas, especially in the northwest and along the south edge of the TP. The climate system on the TP is competitively regulated by the westerlies, Asian monsoon system, and local land-atmosphere interactions,

Fig. 1 a Model domain and topography in the study and $\mathbf{b}$ land cover types over the Tibetan Plateau used in the land surface model, derived from the United States Geological Survey (USGS) Global Land Cover Characterization (GLCC) database 
which pose a great challenge for climate simulations over the steep mountains (Wang et al. 2018; Bao and Li 2020; Fu et al. 2020).

A number of studies have aimed to reduce uncertainty in climate simulations of the TP (Wang et al. 2014, 2016; Zou et al. 2014; Gao et al. 2016, 2017a; Tang et al. 2017; Lin et al. 2018; Gu et al. 2020). Sensitivity experiments, for example, have revealed that TP climate simulations are sensitive to the choice of land surface model (LSM), and RCMs with the Community Land Model (CLM) exhibit better performance in simulating temperature and precipitation (Wang et al. 2014). It has also been found that land-surface processes and large-scale forcing play different roles in dynamic downscaling, forcing datasets with smaller trend biases perform better, and LSMs exert a greater influence on downscaling simulations (Gao et al. 2017a). The soil waterheat physics associated with soil freezing-thawing processes in the CLM has a significant effect on surface energy flux, the overlying atmosphere, and the TP climate, and the precipitation overestimation by RCMs is appreciably alleviated by revising the soil water-heat physics (Wang et al. 2016). These studies highlight the importance of the LSM in accurate RCM simulations.

In addition, convection is considered to be one of the most critical physical processes affecting the occurrence and amount of precipitation (Kukulies et al. 2020; Niu et al. 2020). Due to the small scale of convective clouds, cumulus parameterization schemes (CPSs) have been introduced into GCMs and RCMs to resolve the convective-scale processes (Anthes 1977; Tiedtke 1989; Arakawa 2004). The CPS is often considered to be a primary error source in precipitation simulations (Gao et al. 2016). Therefore, the sensitivity of precipitation to different CPSs has been examined in order to ascertain the reasonable CPS for climate simulations over a region of interest (Gao et al. 2017b; Gu et al. 2020; Niu et al. 2020). Improved precipitation simulation can be attained by means of certain combinations of model parameterizations, even though an optimal model configuration remains elusive. In addition to its influence on precipitation, cumulus convection is a key process in the regulation of atmospheric moisture flux, which fundamentally influences the water balance and radiation forcing, and provides strong feedback to the climate system (Emanuel and Živković-Rothman 1999).

The land-surface hydrological cycle has important implications for land-atmosphere interactions and the climate system (Dirmeyer et al. 2013; Ghosh 2018; Kushwaha et al. 2018; Anwar et al. 2019). With the aid of LSMs, some previous studies have reported the influence of runoff on the surface hydrological cycle and energy balance (Wang et al. 2008; Li et al. 2011). According to the sensitivity experiment that replaces the soil hydrological scheme in the LSM, the use of the Variable Infiltration Capacity (VIC) scheme in place of the TOPMODEL (TOP) scheme better reproduces observed soil hydrological variability; in addition, the ability to simulate evapotranspiration (latent heat) is also enhanced due to the interaction of runoff and soil moisture (Wang et al. 2008). Changes in the hydrological cycle have an influence on regional climate because the water cycle is accompanied by energy exchange. RCM simulation experiments have suggested that the runoff scheme is indeed able to clearly influence the hydrological cycle and surface climate in Africa (Anwar et al. 2019). Yet RCM performance is commonly region-dependent, and it is unclear how land-surface hydrology schemes (LSHSs) influence the TP climate. RCM experiments configured with different CPSs and an LSM can generate significantly different climate simulation results (Gao et al. 2016; Niu et al. 2020). It is also of great interest to examine whether different configurations of CPSs and LSHSs will lead to climate simulation improvements. This could help to more deeply comprehend the climate system on the TP and provide atmospheric forcing data for further fine-scale modeling, such as double-nested (Gu et al. 2020) or convection-permitting simulation (Prein et al. 2015). Thus, the objective of this study was to investigate the roles CPS and LSHS play in the simulation of regional climate and to explore how key physical processes represented by these parameterization schemes act on climate.

The remainder of this manuscript is organized as follows. Section 2 describes the model and data used in this study. Section 3 presents the comparisons between the observations and simulations, including air temperature and precipitation (large-scale and convective) as well as the diurnal cycle of precipitation. We also investigate the impacts of the CPS and LSHS on the surface energy and water budgets in Sect. 4 . Section 5 comprises an analysis of the moisture flux transport and upward motion in order to account for the different precipitation simulations. The conclusions of this investigation are summarized in Sect. 6, along with a brief summary of the implications of this study.

\section{Model, experiment design, and validation data}

\subsection{RegCM4 description}

The RCM used in this study was the Abdus Salam International Centre for Theoretical Physics (ICTP) RegCM version 4.7. The RegCM is a limited-area model using a terrainfollowing $\sigma$-pressure vertical coordinate and an Arakawa B horizontal grid system (Giorgi et al. 2012). The model's dynamic components include the latest non-hydrostatic version and a hydrostatic version of the MM5 with improvements to the coupling with an advanced and sophisticated LSM (CLM3.5 and CLM4.5, Oleson et al. 2008, 2013). The physical parameterizations in the model contain the 
radiation package of the National Center for Atmospheric Research (NCAR) community climate system model version 3 (CCSM3) (Kiehl et al. 1996); the Rapid Radiation Transfer Model (RRTM) (Mlawer et al. 1997); the planetary boundary layer (PBL) scheme developed by Holtslag and Boville (1993), which allows for non-local transport in the convective boundary layer; the large-scale cloud and precipitation scheme (Pal et al. 2000), known as the SUBgrid EXplicit moisture scheme (SUBEX), which accounts for sub-grid variability in clouds; and several optional CPSs, such as the Kuo (Anthes 1977), Kain-Fritsch (Kain and Fritsch 1993), Grell (Grell 1993), MIT-Emanuel (hereafter MIT) (Emanuel 1991), and Tiedtke (Tiedtke 1989). Overall, many aspects of the RegCM4's simulation capabilities have been updated (Giorgi et al. 2012; Giorgi 2019), including the representation of climate variables over multiple Coordinated Regional Climate Downscaling Experiment (CORDEX) domains.

\subsection{Convective parameterization and land-surface hydrology schemes}

Two CPSs, the Grell and MIT schemes, were employed in this study because they have been demonstrated to exhibit acceptable performance in simulating climate variables and have been commonly used (e.g., Giorgi et al. 2004; Zou et al. 2014; Gao et al. 2016; Wang et al. 2016). The Grell scheme (1993) supposes that clouds are represented by two steady-state circulations: an updraft and a downdraft. Mixing occurs only in the cloud base and top. The mass flux is constant with height and there is no entrainment or detrainment along the cloud edges. Convection is activated when an elevated parcel achieves moist convection. Heating and moistening depend on the mass fluxes and detrainment at the cloud base and top. The cooling effect of moist downdrafts is considered.

The MIT scheme is the most complex, as it describes the cumulus processes, and considers cloud mixing and ice processes. This method assumes that cloud mixing is highly episodic and inhomogeneous, and convective fluxes are based on an idealized model of subcloud-scale updrafts and downdrafts (Emanuel 1991). If the neutral buoyancy level is higher than the cloud base level, convection is triggered. Between the two levels, the air is lifted and a portion of the condensed water vapor will form precipitation while the remainder forms cloud. The mixing entrainment and detrainment rates are determined by the vertical gradients of buoyancy in clouds. The cloudy air mixed with its environment at each level is proportional to the undiluted buoyancy rate of change with height. A formulation of the auto-conversion of cloud water into precipitation inside cumulus clouds is also contained in the scheme.

The LSM CLM4.5 was selected since it has parameterized the soil-vegetation-atmosphere interaction processes and includes more elaborate surface characteristics compared with its predecessor, CLM3.5. Two LSHSs in the CLM4.5 were tested in the present work, i.e. the default and the VIC. The default LSHS in the CLM4.5 is the simple TOPMODEL-based (Beven and Kirkby 1979) runoff model (SIMTOP) described by Niu et al. (2005), hereinafter referred to as the TOP scheme. The TOP scheme for parameterizing runoff is based on the treatment of fractional saturated areas, which is dependent on the topographic characteristics and soil moisture state of a grid cell.

The VIC land-surface hydrology model was also provided as an alternative scheme. The VIC scheme is derived from the variable infiltration capacity LSM (Liang et al. 1994). Three soil layers with variable depths are designed in the VIC scheme to reflect the soil's dynamic response to rainfall events for surface runoff generation and to depict subsurface runoff generation. In contrast with the TOP scheme, the fractional saturated area is defined by soil moisture in the top two VIC layers and a parameter that controls the shape of the soil moisture-holding capacity curve. Therefore, this scheme hypothesizes that the soil moisture-holding capacity curve can represent the spatial inhomogeneity of soil moisture-holding capacity in the top VIC layers. Subsurface runoff generation is more intricate and considers the subsurface flow rate, storage capacity, and soil water of the third layer. For more details and relevant formulas, refer to Li et al. (2011) and Oleson et al. (2013).

\subsection{Numerical experiments and validation datasets}

To evaluate the performance of different CPSs and LSHSs and explore the interactions between them, four experiments using the RegCM4-CLM4.5 model covering the TP and its surrounding areas (Fig. 1a) were conducted: (1) Grell and CLM4.5 with TOP (hereinafter referred to as GTP), (2) Grell and CLM4.5 with VIC (GVC), (3) MIT and CLM4.5 with TOP (MTP), and (4) MIT and CLM4.5 with VIC (MVC). Different combinations of CPSs and LSHSs were used for the following reasons: (1) When comparing the GTP and MTP or GVC and MVC simulations, in which the same LSHS was used, the climate effects caused by different CPSs could be detected; (2) Comparing the GTP and GVC or MTP and MVC simulations, in which the same CPS was used, could detect the climate effects caused by different LSHSs; (3) By further comparing the two pairs of simulations, the interactions between CPSs and LSHSs could be revealed. For easier understanding, these were tabulated in Table 1. According to the United States Geological Survey (USGS) Global Land Cover Characterization (GLCC) database, the land cover types used in the land surface model include short grass, semi-desert, desert, tundra, and deciduous broadleaf tree (Fig. 1b). 
Table 1 Design of the four simulations with different combinations of cumulus parameterization schemes (CPSs) and land-surface hydrology schemes (LSHSs)

\begin{tabular}{|c|c|c|c|c|}
\hline & \multicolumn{2}{|l|}{ LSHSs } & \multicolumn{2}{|l|}{ CPSs } \\
\hline & TOP & VIC & Grell & MIT \\
\hline GTP & \multirow[t]{2}{*}{ Yes } & & \multicolumn{2}{|l|}{ Yes } \\
\hline GVC & & Yes & Yes & \\
\hline MTP & \multirow[t]{2}{*}{ Yes } & & & Yes \\
\hline MVC & & Yes & & Yes \\
\hline Objective & $\begin{array}{l}\text { Climate effect of } \\
\text { CPS with the TOP } \\
\text { scheme }\end{array}$ & $\begin{array}{l}\text { Climate effect of } \\
\text { CPS with the VIC } \\
\text { scheme }\end{array}$ & $\begin{array}{l}\text { Climate effect of } \\
\text { LSHS with the Grell } \\
\text { scheme }\end{array}$ & $\begin{array}{l}\text { Climate effect of } \\
\text { LSHS with the MIT } \\
\text { scheme }\end{array}$ \\
\hline & \multicolumn{4}{|c|}{$\begin{array}{l}\text { Comparing the two pairs of experiments could reveal the impacts of the interactions between } \\
\text { CPSs and LSHSs on simulated climate }\end{array}$} \\
\hline
\end{tabular}

The simulation domain in the four experiments was centered at $30^{\circ} \mathrm{N}$ and $88^{\circ} \mathrm{E}$, with a $20 \mathrm{~km}$ horizontal grid spacing (a $224 \times 152$ grid mesh). The horizontal resolution adopted in the study is as fine as those employed by RCMs in recent studies (e.g., Gao et al. 2011; Ménégoz et al. 2013), but is higher than that in the second phase of the CORDEX $\left(0.22^{\circ}\right.$ resolution, $\left.\sim 25 \mathrm{~km}\right)$ over multiple-domains (Giorgi 2019; Wang et al. 2021). The higher resolution (20 km) relative to large-scale models enables the simulation of largescale phenomena that contains small-scale processes, such as regionally localized features related to small-scale orography. There were 23 vertical sigma layers, with the model top at $50 \mathrm{hPa}$. In each direction, 12 grid points were allocated to be used as a lateral buffer zone. The 6-hourly ERA-Interim data developed by the European Centre for Medium-Range Weather Forecasts (ECMWF) (Dee et al. 2011) at a resolution of $0.75^{\circ}$ (at a 79-km grid spacing) were employed to derive the initial and lateral boundary conditions for the RegCM4-CLM4.5 runs. Sea surface temperatures (SSTs) were provided by NOAA optimal interpolation weekly SST data at a $1^{\circ} \times 1^{\circ}$ resolution (Reynolds et al. 2002). The model integration period of the four experiments spanned January
2005-January 2017, in which the first year (January-December 2005) was considered as spin-up time and excluded in the analysis. The physical configuration of the four experiments is summarized in Table 2.

We used the CN05.1 gridded observational dataset with a resolution of $0.25^{\circ} \times 0.25^{\circ}$ covering whole mainland China (Wu and Gao 2013), which was interpolated from over 2400 meteorological stations covering the period 1961-2017, as observations (OBS) to validate the simulated surface air temperature and precipitation. The Integrated Multi-satelliteE Retrievals satellite precipitation product-global precipitation measurement (GPM) mission (IMERG) (Hou et al. 2014), with a resolution of $0.1^{\circ} \times 0.1^{\circ}$ and measurements every $30 \mathrm{~min}$, was also chosen to evaluate the model-simulated precipitation, especially for the diurnal cycle. The GPM was launched in 2014, and the IMERG is the successor of the multi-satellite 3B42 dataset from the Tropical Rainfall Measuring Mission (TRMM) and has been retrospectively processed back through the TRMM era, beginning from June 2000 to the present (Huffman et al. 2020). The half-hourly precipitation was aggregated to determine the hourly and daily precipitation. Total cloud
Table 2 RegCM4 model configuration and experimental settings in the study

\begin{tabular}{ll}
\hline Contents & Description \\
\hline Domain & TP domain and surrounding area \\
Horizontal grid & $224 \times 152(\Delta \mathrm{X}=20 \mathrm{~km})$ \\
Vertical layers (top) & $23(50 \mathrm{hPa})$ \\
Planetary boundary layer & Holtslag \\
Cumulus parameterization scheme (CPS) & $(1)$ Grell scheme \\
& $(2)$ MIT-Emanuel scheme \\
Land-surface hydrological scheme (LSHS) & $(1)$ TOPMODEL $(\mathrm{CLM} 4.5)$ \\
& $(2)$ VIC $(\mathrm{CLM} 4.5)$ \\
Grid-scale precipitation & Subgrid explicit moisture scheme (SUBEX) \\
Ocean flux scheme & Zeng \\
Lateral boundary condition & ERA-Interim reanalysis $\left(0.75^{\circ}\right)$ \\
SST boundary condition & Weekly NOAA $\left(1^{\circ}\right)$ \\
Simulation period & January 2005-January 2017 \\
\hline
\end{tabular}


fraction and radiation data from the Clouds and the Earth's Radiant Energy System (CERES) Edition 4.1 Energy Balanced and Filled (EBAF) data product $\left(1.0^{\circ} \times 1.0^{\circ}\right.$, March 2000-November 2019) (Loeb et al. 2018) was used to validate the model-simulated energy balance. The bias in the cloud fraction has been corrected based on observations from Cloud-Aerosol Lidar and Infrared Pathfinder Satellite Observations (CALIPSO) and CloudSat (Kato et al. 2018). Meanwhile, we also referred to the newly released ERA5 reanalysis dataset $\left(0.25^{\circ} \times 0.25^{\circ}, \sim 31 \mathrm{~km}\right)$ from the ECMWF (Hersbach et al. 2018) to evaluate the performance of the RCM and to further identify the associated error sources. The ERA5 is an improvement over its ERA-Interim predecessor in terms of a higher spatiotemporal resolution and the capability to integrate ample amounts of reprocessed observations into global estimates using an advanced earth system model and data assimilation system (Hersbach et al. 2020). The other two satellite-derived datasets including evapotranspiration and surface soil moisture on the TP, available from the National Tibetan Plateau Data Center (http://data.tpdc. ac.cn/en/), were used to evaluate the simulations. Monthly mean evapotranspiration with a resolution of $0.1^{\circ}$ from 2001 to 2018 was estimated by the surface energy balance system driven by the Moderate Resolution Imaging Spectroradiometer (MODIS) satellite data and China Meteorological Forcing Dataset, during which the accuracy of surface turbulence fluxes was improved through implementing the sub-grid orography drag scheme (Han et al. 2020). A random forest method was used to produce a high-accuracy soil moisture product (referred to as AMSR) a resolution of $0.25^{\circ}$ from 20 June 2002 to 30 December 2018 by adopting the advanced microwave scanning radiometer for earth observing system (AMSR-E), the AMSR2, and tracking brightness temperatures as well as related auxiliary data (Qu et al. 2019; Chai et al. 2020).

Given that the climate sensitivities of the CPS and LSHS are more connected with changes in hydrologic variables, we mainly focused on the monsoon season (May-September), during which $83.8 \%$ of the total precipitation occurs, according to the GPM data. To facilitate comparison, the model outputs, GPM precipitation data, ERA5 data, and evapotranspiration data were bilinearly interpolated into a common resolution with the OBS grid. Given the effects on air temperature of the elevation differences between the simulations and reference data, the simulated air temperatures were corrected with reference to the elevation of the OBS and ERA5 using a lapse rate of $0.65{ }^{\circ} \mathrm{C} 100 \mathrm{~m}^{-1}$ (Li et al. 2013). The regionally-averaged air temperatures and precipitation during the wet season simulated by the RCM were evaluated against observations by means of three statistical parameters, including spatial correlation coefficient (SCOR), bias, and root-mean-square error (RMSE). The simulated 3-hourly precipitation was interpolated to 1 -hourly precipitation on a universal coordinated time (UTC) frame by a simple linear interpolation method between two timesteps. Then the precipitation from the model simulations and GPM were converted from the UTC frame to the Beijing time frame $(\mathrm{UTC}+8)$. Following Ou et al. (2020), precipitation frequency for a given hour of day is defined as the percentage of the total number of hours with measurable precipitation $\left(\geq 0.1 \mathrm{~mm} \mathrm{~h}^{-1}\right)$ to the total non-missing hours during the wet season; precipitation intensity is the cumulative hourly precipitation for a given hour of the day divided by the total number of hours with measurable precipitation during that given hour of day in the wet season.

\section{Evaluation of air temperature and precipitation simulations}

\subsection{Spatial distribution of air temperature}

The OBS and ERA5 data revealed that air temperature exhibits clear spatial patterns closely related to terrain, i.e., it is cold in high-altitude areas and warm in low-altitude areas (Fig. 2). The RegCM4 could satisfactorily reproduce the spatial patterns of air temperature (not shown), with high SCORs (>0.88) (Table 3). Compared with OBS, the GTP yielded an overall temperature that was $0.1^{\circ} \mathrm{C}$ warmer. A significantly large cold bias was clearly evident on the western $\mathrm{TP}$, reaching $-7.0^{\circ} \mathrm{C}$, although a warm bias was found over most of the TP. The RegCM4 configured with the Grell scheme simulated slightly warmer temperatures, which is consistent with our previous study using the same CPS (Wang et al. 2016). Among the four simulations, the GTPsimulated temperature was much closer to OBS, as indicated by the smallest bias and RMSE. This suggests that the GTP outperformed the other models in simulating air temperature. For the experiment with the MIT scheme (Fig. 2e), the MTP simulated a lower temperature than OBS, exhibiting a significant cold bias on the western TP and a warm bias on the eastern TP. The cold bias was greater than that in the simulation with the Grell scheme, while the warm bias on the central TP was smaller. Therefore, the MIT scheme tended to aggravate the cold bias but slightly alleviated the warm bias. When configured with the VIC scheme (Fig. 2d and $\mathrm{f}$ ), the GVC model simulated warmer temperatures relative to OBS, while the MVC model simulated colder temperatures. Compared with the simulations of the TOP scheme, the VIC scheme increased temperatures, especially on the central and eastern TP, which enhanced the warm bias in that region but helped offset the cold bias. In addition, configured with the TOP scheme, the inter-model temperature differences caused by different CPSs were greater than those configured with the VIC scheme, notably on the central-western 
(a) OBS

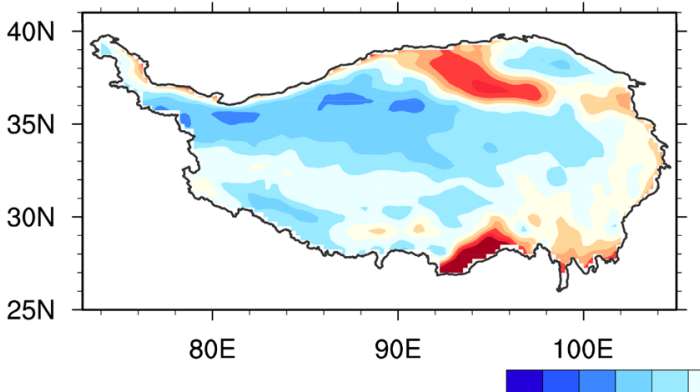

(c) GTP-OBS

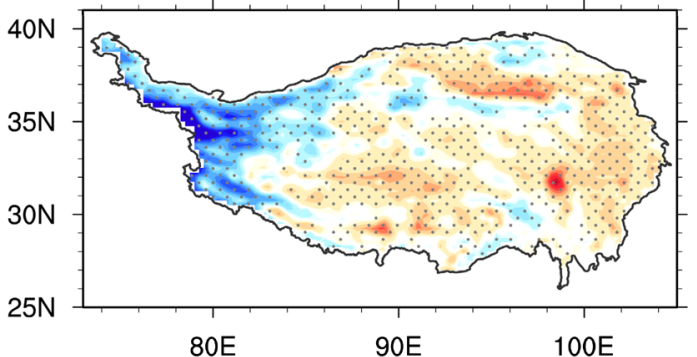

(e) MTP-OBS

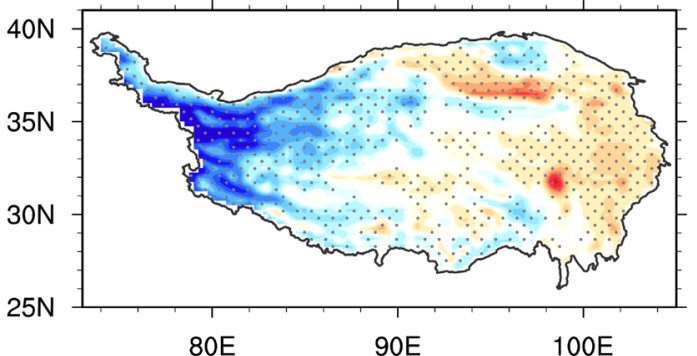

(g) GTP-ERA5

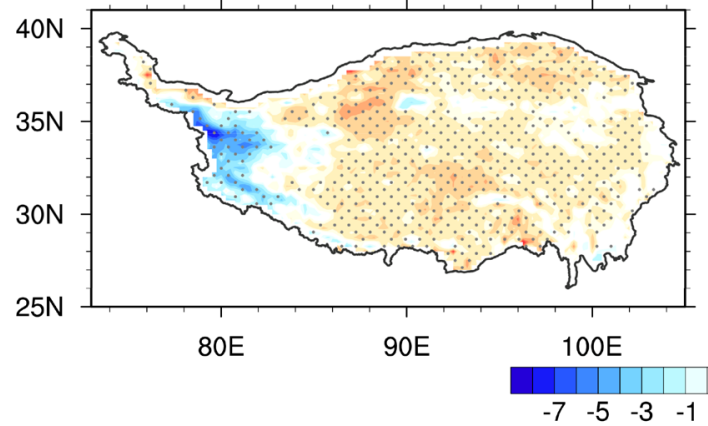

$\begin{array}{llll}-7 & -5 & -3 & -1\end{array}$

Fig. 2 Spatial distribution of air temperature from a OBS and $\mathbf{b}$ ERA5, differences between simulations and OBS (c GTP-OBS, d GVC-OBS, e MTP-OBS, f MVC-OBS), differences between simulations and reference data (g GTP-ERA5, h MTP-ERA5) during the

TP. This suggests that there were some interactions between CPSs and LSHSs impacting air temperature.

A number of uncertainties associated with the air temperature simulation should be acknowledged. A distinct cold bias appeared on the western TP, which is in accordance with the previous studies based on the RegCM4 simulations (b) ERA5

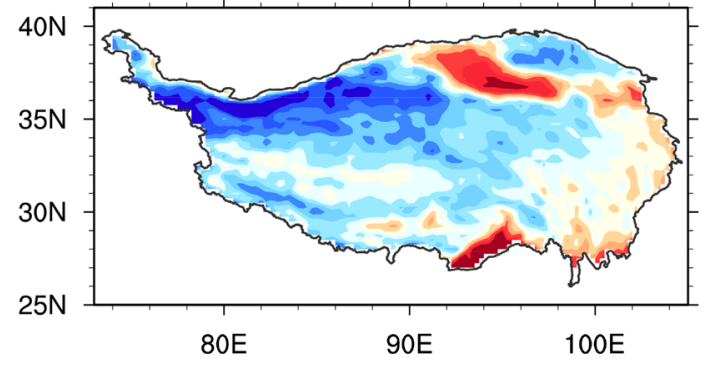

(d) GVC-OBS

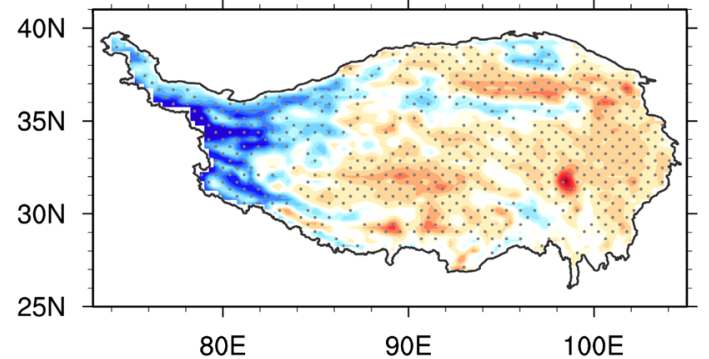

(f) MVC-OBS

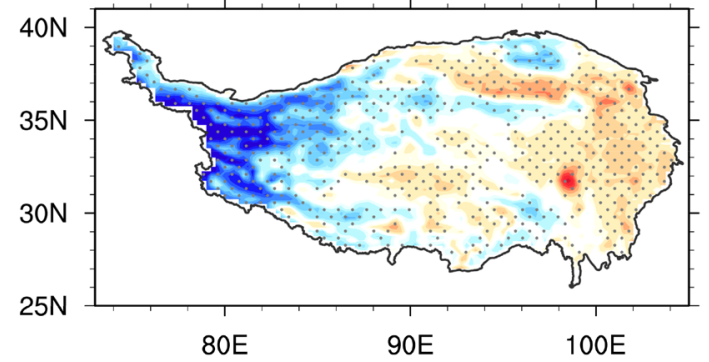

(h) MTP-ERA5 Mean $=0.2^{\circ} \mathrm{C}$

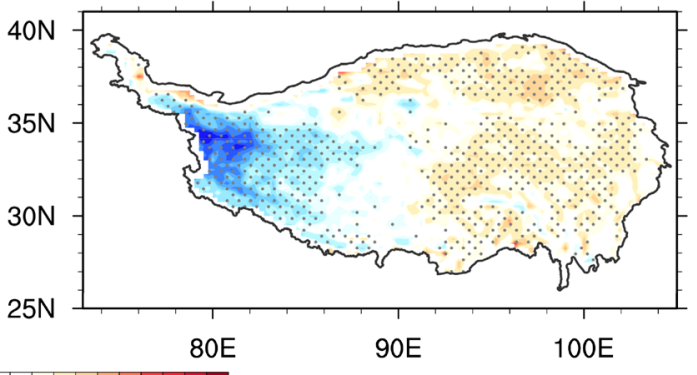

wet season (May-September). The mean differences for $(\mathbf{g}, \mathbf{h})$ are labelled in the upper right corner of each panel. The dotted points denote the difference significant at the $95 \%$ confidence level

(Gao et al. 2011; Wang et al. 2014, 2016; Gu et al. 2020). Lower air temperatures on the western TP were caused by the driving ERA-Interim (Wang et al. 2017), which probably passed the cold bias of the driving data to the RegCM4 simulations. The overestimated surface albedo discussed below could also be responsible for the cold bias. Compared 
Table 3 Spatial correlation coefficient (SCOR), Bias, and RMSE between four groups of simulations and observed temperature $\left({ }^{\circ} \mathrm{C}\right) /$ precipitation $\left(\mathrm{mm} \mathrm{day}^{-1}\right)$ over the TP during the wet season (May-September)

\begin{tabular}{lllll}
\hline & GTP & GVC & MTP & MVC \\
\hline SCOR & $0.90 / 0.53(0.77)$ & $0.88 / 0.53(0.75)$ & $0.90 / 0.56(0.70)$ & $0.89 / 0.57(0.69)$ \\
Bias & $0.1 / 4.7(4.1)$ & $0.2 / 4.4(3.8)$ & $-0.8 / 3.3(2.9)$ & $-0.6 / 3.2(2.7)$ \\
RMSE & $2.4 / 5.9(5.2)$ & $2.7 / 5.7(5.0)$ & $2.8 / 4.4(4.0)$ & $2.9 / 4.3(4.0)$ \\
\hline
\end{tabular}

The statistical values between the GPM precipitation data and model simulations are shown in brackets

to the eastern $\mathrm{TP}$, lower air temperatures are concentrated on the western TP (Fig. 2a and b) where higher altitudes tend to generate a larger fraction of snow cover (Yang et al. 2019). The snow-albedo feedback exerts a stronger influence on surface air temperatures on the western TP. Moreover, uncertainties in the observation data could introduce bias, since the observational network is fairly sparse on the western TP (Wu and Gao 2013; Wang et al. 2018).

The temperature difference between the GTP and ERA5 (Fig. $2 \mathrm{~g}$ ) roughly resembled that between the GTP and OBS, although there was a smaller cold bias on the western TP and a warm bias over a larger area. Overall, the regional average temperature from the GTP simulation was $1.1{ }^{\circ} \mathrm{C}$ higher than the ERA5 data. A similar spatial pattern was also found in the difference between the MTP and ERA5, although a much smaller bias was presented, suggesting temperatures of the MTP simulation were close to the ERA5 data. The temperature differences between the simulations with the VIC scheme and the ERA5 (figure not shown) and OBS were also similar. The broadly consistent spatial pattern of the temperature difference between the RCM simulations relative to OBS and ERA5 indicates that the ERA5 dataset as reference data can help interpret the physical processes responsible for the RegCM4 performance, as described in Sect. 4.

\subsection{Precipitation}

\subsubsection{Spatial distribution of precipitation}

Similar to air temperature, the spatial distribution of precipitation from the OBS, GPM, and ERA5 data during the wet season is presented in Fig. 3a-c. Jointly affected by the Asian summer monsoon, westerlies, and local processes, precipitation exhibits an evident spatial pattern, decreasing from southeast to northwest. The RegCM4 captured the observed spatial pattern (not shown) but simulated generally higher precipitation than the observations. Compared with the observed data (OBS and GPM), the GTP substantially overestimated precipitation (Fig. 3a1 and b1), with an overall bias of 4.1-4.7 mm day ${ }^{-1}$ (Table 3 ). The bias was especially strong on the southeastern TP, which has steep, complex terrain and intense precipitation. There was a portion of the southwestern TP in which precipitation was underestimated, and the areas with precipitation amounts similar to those of the observed data were located in the Qaidam Basin and part of the western TP. When using the MIT scheme (Fig. 3a3 and b3), the overestimation, particularly on the southeastern TP, was largely reduced by the MTP model, although the precipitation was still overestimated over most of the TP, and the underestimation was slightly decreased. As a result, the overall overestimation was reduced, by around $30 \%$. In addition, the models configured with the VIC scheme could also reduce the wet bias, although the reduction was mainly located on the northern and central TP, which receives moderate precipitation amounts. For the MVC simulation, the reduction in the wet bias, around 34\% relative to the GTP simulation, was more apparent on the western and southeastern TP compared to the other three simulations, indicating a significant improvement for precipitation simulation. Although the MIT scheme could effectively remove some wet biases, precipitation in the MVC simulation was still overestimated, especially on the southeastern TP. Another CPS, the Tiedke scheme (Kain and Fritsch 1993), has been suggested to reduce precipitation bias, but it is often confined to a limited area and leads to higher air temperatures (Gu et al. 2020). Similar to temperature difference, when configured with the TOP scheme, different CPSs caused precipitation differences between models that were more prominent than those configured with the VIC scheme. This phenomenon also demonstrates that precipitation can be influenced by the LSHS via the land-atmosphere interactions discussed below.

Statistically, the SCORs between the model simulations and the OBS (GPM) exceeded 0.53 (0.69) (Table 3), suggesting that all models could reasonably reproduce the spatial variability of precipitation on the TP. On the whole, the MVC exhibited the best skill in simulating TP precipitation during the wet season, as indicated by the smallest bias and RMSE. The GTP and GVC generated noticeably larger RMSEs than the MTP and MVC, highlighting the importance of the CPS for precipitation simulation. There were also some reductions in RMSEs between the model simulations using the VIC scheme and the TOP scheme, again indicating that the LSHS plays a role in precipitation simulation. 
(a) OBS

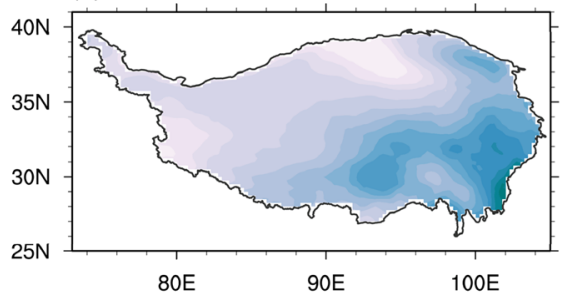

(a1) GTP-OBS

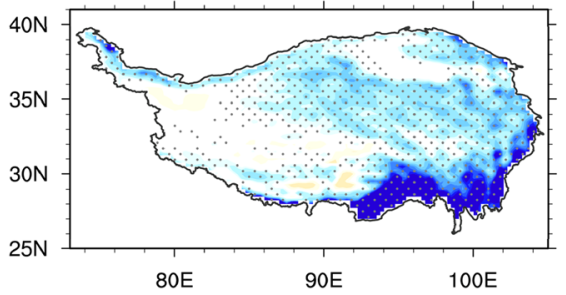

(a2) GVC-OBS

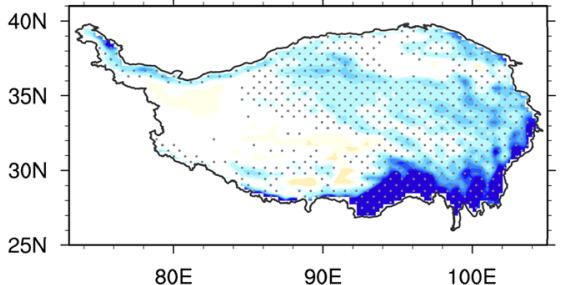

(a3) MTP-OBS

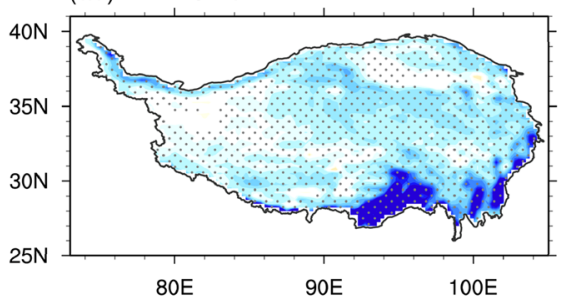

(a4) MVC-OBS

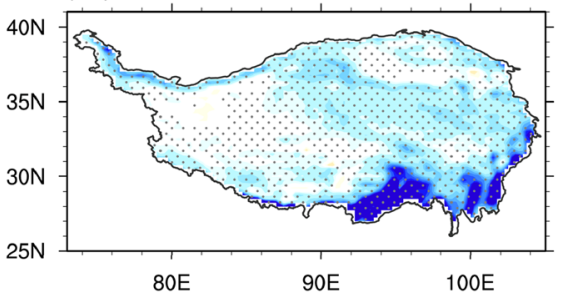

(b) GPM
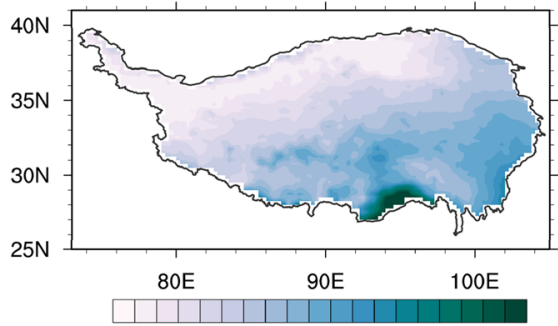

$\begin{array}{llllllllll}0.5 & 1 & 2 & 3 & 4 & 5 & 6 & 8 & 10 & \mathrm{~mm}_{\text {day }}-1\end{array}$ (b1) GTP-GPM

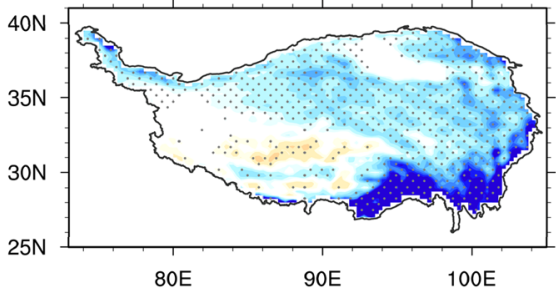

(b2) GVC-GPM

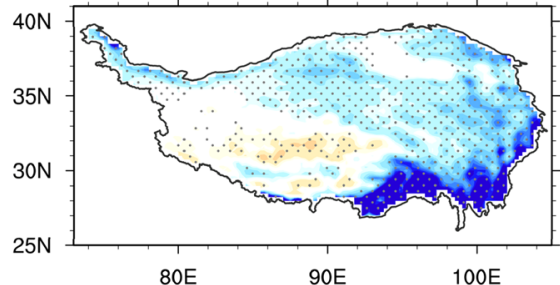

(b3) MTP-GPM

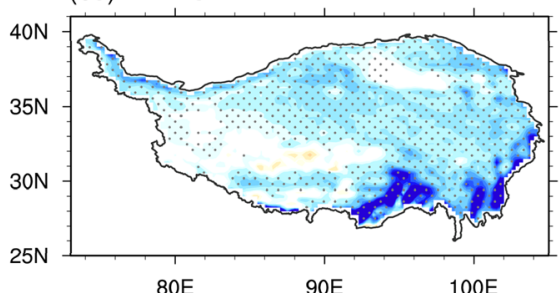

(b4) MVC-GPM

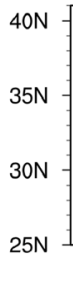

(c) ERA5

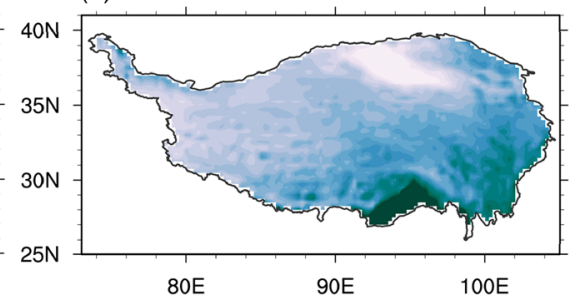

(c1) GTP-ERA5 Mean $=2.4 \mathrm{~mm} /$ day

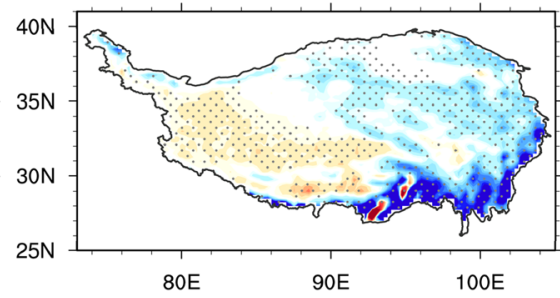

(c2) GVC-ERA5 Mean $=2.1 \mathrm{~mm} /$ day

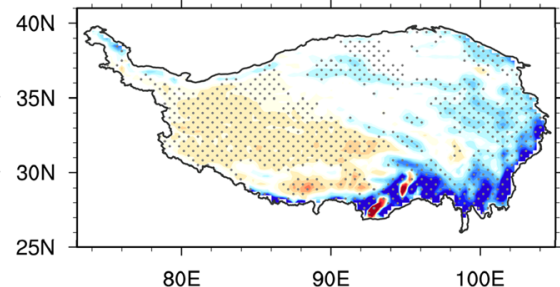

(c3) MTP-ERA5 Mean $=1.0 \mathrm{~mm} /$ day

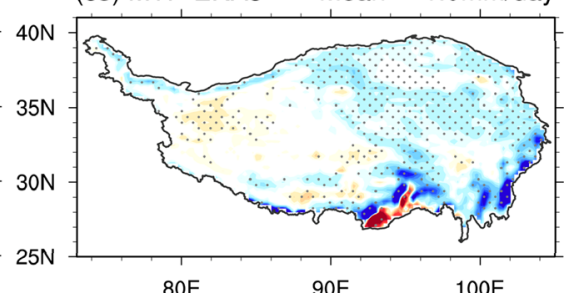

(c4) MVC-ERA5 Mean $=0.8 \mathrm{~mm} /$ day

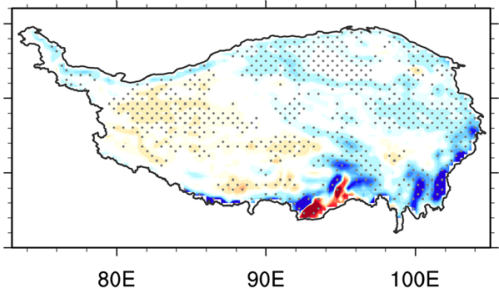

Fig. 3 Spatial distribution of precipitation from a OBS, b GPM, and c ERA5, differences between the model simulations and the reference data (a1-a4 for OBS, b1-b4 for GPM, c1-c4 for ERA5) during the wet season (May-September). The mean differences for simulations

Most available stations are located in valleys and there is a sparse observation network in the west of the TP. Thus, accurate characterization of spatiotemporal precipitation patterns is hampered. Here, the GPM (IMERG) was jointly used as the reference data due to its better spatial and ERA5 are labelled in the upper right corner of each panel. The dotted points denote the difference significant at the $95 \%$ confidence level

coverage than station-based observations. Furthermore, the GPM provides a uniform and gauge-calibrated dataset (Ma et al. 2016; Wang et al. 2018), performing well in reproducing probability density function and diurnal variability of precipitation (Tang et al. 2016). The GPM IMERG V06 
agreed well with the observed daily precipitation over the TP during 2000-2019 (Ma et al. 2021). However, some studies have pointed out that the GPM data contains low precipitation amounts (Kukulies et al. 2020), especially on the western TP (Li et al. 2020) because of its large missing ratio, especially for snowfall. The GPM-retrieved precipitation outperforms the TRMM in detecting daily rainfall with reference to ground-based stations (Xu et al. 2017), and the underperformance (large false alarming ratio) of the TRMM may have an influence on the overall accuracy of the GPM data. Thus, the wet bias of the simulated precipitation can be partly attributed to the underestimation of the GPM precipitation. In addition, the wet bias could be inherited from its forcing-ERA-Interim, which overestimates precipitation, especially on the southern and southeastern TP (Wang et al. 2017). This implies that, with the exception of modifying the $\mathrm{CPS}$, correcting the biases in the driving data is also crucial for obtaining more accurate climate modeling.

The model simulations relative to the ERA5 dataset displayed a spatial pattern of precipitation differences similar to that of the observations (Fig. 3). Comparatively, the overestimation produced by the models was lower when compared with the ERA5. In the GTP and GVC simulations, the substantial wet bias still existed and the area with underestimation was expanded. Based on the comparison results, using the ERA5 dataset is considered appropriate for diagnosing the precipitation bias of the model in the following analysis.

\subsubsection{Comparisons of LSP and CP between the RegCM4 simulations}

Simulated precipitation consists of large-scale precipitation (LSP) and convective precipitation (CP). Their spatial distributions during the wet season as revealed by the ERA5 data are presented in Fig. $4 \mathrm{a} 1$ and a2. Similar to overall precipitation, LSP exhibits a marked spatial gradient, decreasing from southeast to northwest, with minima located in the Qaidam Basin and Qiangtang Plateau. There is also a marked spatial gradient in $\mathrm{CP}$, gradually decreasing from south to north. The spatial distribution of the ratio of $\mathrm{CP}$ to total precipitation reveals that $\mathrm{CP}$ contributes significantly to total precipitation on the southern TP (Fig. 4a3); a maximum is clearly apparent on the southwestern TP (including the Qiangtang Plateau), and another large area is located on the southeastern TP. The average contribution is $53.7 \%$ over the entire TP.

Compared with the ERA5 data, the GTP simulation produced significantly higher LSP, particularly on the southeastern TP (Fig. 4b1). The overestimation $(\sim 112 \%)$ largely contributed to the wet precipitation bias, during which LSP accounted for $68 \%$ of the total precipitation in the GTP simulation. With reference to CP in the ERA5 data, the GTP simulated a smaller value over most of the TP, but still simulated a higher value on the southeastern TP (Fig. 4b2). The contribution of CP to total precipitation in the GTP simulation (32\%) was lower than the ERA5 data (Fig. 4b3). Meanwhile, the MTP-simulated LSP was slightly higher than the ERA5 data, mainly on the eastern and southeastern TP, and there was also some patchy overestimation of $\mathrm{CP}$, situated between $90^{\circ} \mathrm{E}$ and $100^{\circ} \mathrm{E}$. This comparison suggests that the overestimated LSP was significantly reduced by the MIT scheme, and the overestimation of CP on the southeastern TP in the GTP simulation was somewhat reduced by the MTP simulation. In this case, the spatial distribution of the contribution of CP to total precipitation in the MTP simulation was more consistent with the ERA5 data; specifically, the contribution was enhanced to a proportion of 50\% (Fig. 4d3).

Regarding the influence caused by the LSHS, the GVCsimulated LSP was also higher than the ERA5 data, but lower than the GTP simulation. There was little difference in LSP between the MVC and MTP simulations, meaning that the VIC scheme could reduce the LSP overestimation, and this reduction was more effective in the model configuration with the Grell scheme. The VIC scheme could also decrease $\mathrm{CP}$, which benefits the case of $\mathrm{CP}$ overestimation, such as the simulation with the MIT scheme, in which the contribution of CP was slightly decreased. In comparison, the VIC scheme had a larger impact on CP than LSP.

As for the contribution of $\mathrm{CP}$ to total precipitation, a previous WRF simulation demonstrated that the contribution of CP ranges from 70 to $80 \%$ on the central TP, and approaches $100 \%$ in the Himalayas during the summer months (Maussion et al. 2014). The GPM 3GPROF satellite precipitation product, however, provides a much lower estimate of the contribution that varies between 10 and $40 \%$ on the eastern TP from May to September (Kukulies et al. 2020). Our results revealed that the location of the maximum CP contribution to precipitation was on the central and eastern TP, which was in accordance with the WRF simulation and the results of Sugimoto and Ueno (2010). During the wet season, the maximum contribution of CP to precipitation varied from 60 to $80 \%$, the regionally-averaged contribution in the ERA5 data was 54\%, and the contributions in the simulations with the Grell and MIT schemes were $<32 \%$ and $\sim 50 \%$, respectively. This demonstrates that the contributions differ from previous studies, i.e., the WRF simulation (Maussion et al. 2014) and satellite data (Kukulies et al. 2020), and are somehow dataset-dependent. One of the possible explanations involves the different CPSs used and the satellite precipitation retrieval algorithm. The WRF simulation used the new Grell-Denvenyi 3 scheme (Maussion et al. 2014), while the ERA5 (Cy41r2) utilized the modified Tiedtke (1989) scheme, including a complete revision of the entrainment and coupling with the large-scale factors, to handle convection (Hersbach et al. 2018). Meanwhile, the satellite 
(a) Large-scale precipitation

(a1) ERA5

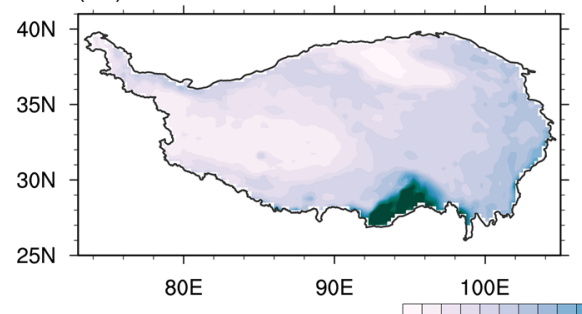

$\begin{array}{lllllllll}0.5 & 1 & 2 & 3 & 4 & 5 & 6 & 8 & 10 \mathrm{~mm} \text { day }^{-1}\end{array}$

(b1) GTP-ERA5 Mean $=2.6 \mathrm{~mm} /$ day

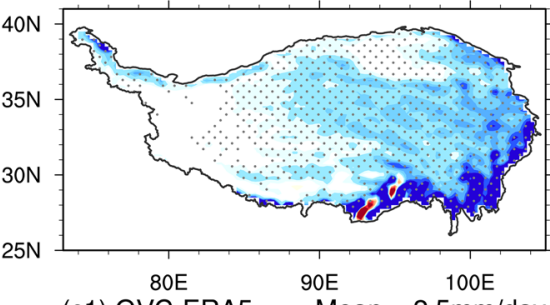

(c1) GVC-ERA5 Mean $=2.5 \mathrm{~mm} /$ day

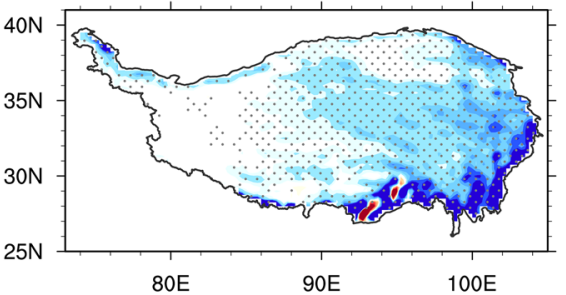

(d1) MTP-ERA5 Mean $=0.7 \mathrm{~mm} /$ day

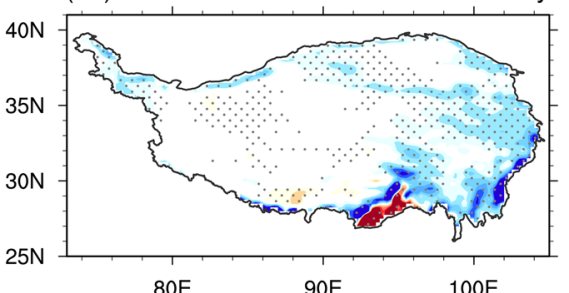

(e1) MVC-ERA5 Mean $=0.7 \mathrm{~mm} / \mathrm{day}$
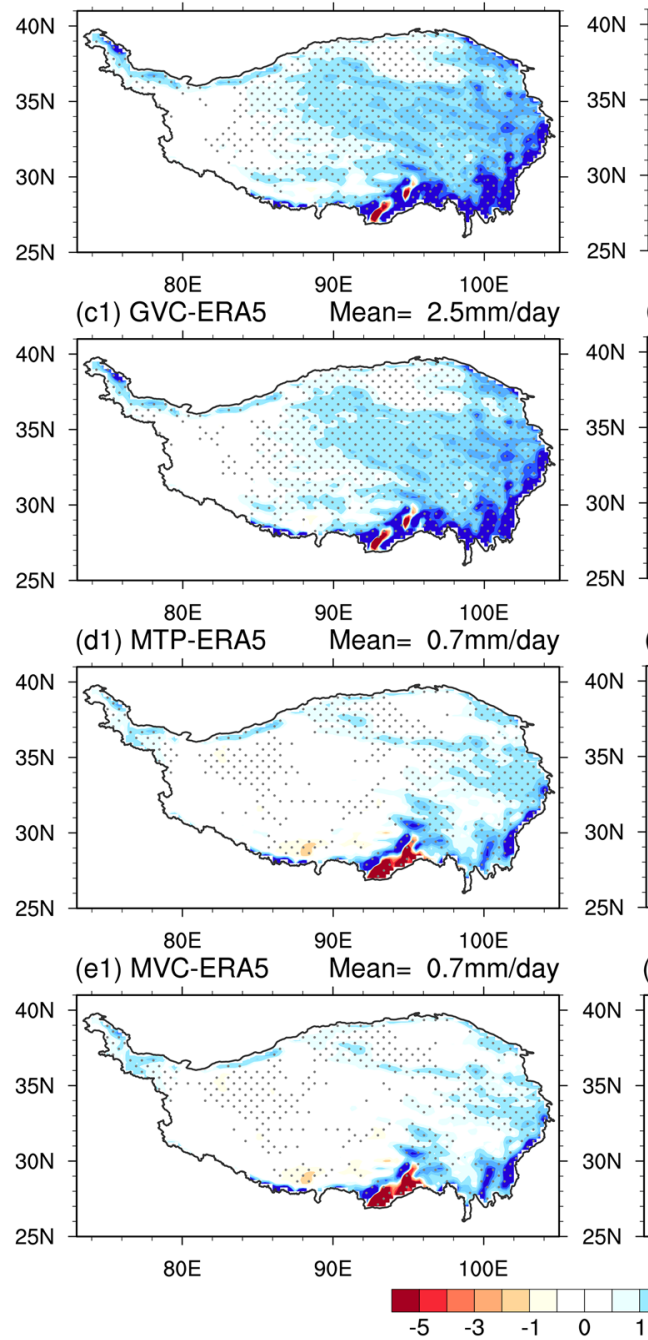

(b2) GTP-ERA5

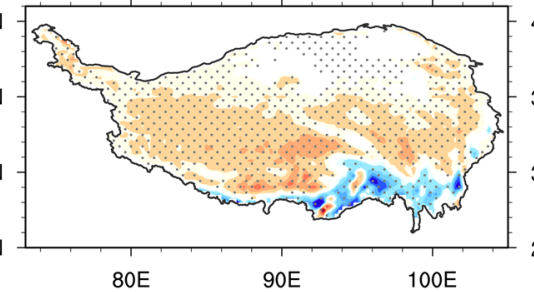

(c2) GVC-ERA5 Mean $=-0.5 \mathrm{~mm} /$ day

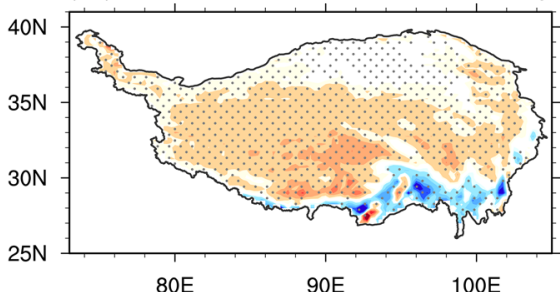

(d2) MTP-ERA5 Mean $=0.3 \mathrm{~mm} /$ day

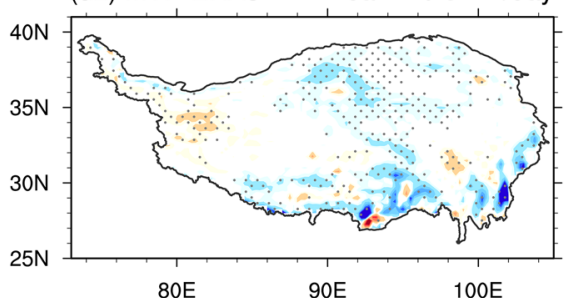

(e2) MVC-ERA5 Mean $=0.2 \mathrm{~mm} /$ day

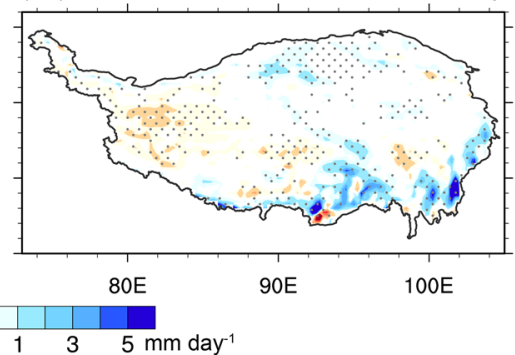

(b) Ratio of CP to total precipitation

(a3) ERA5 $\quad 53.7 \%$

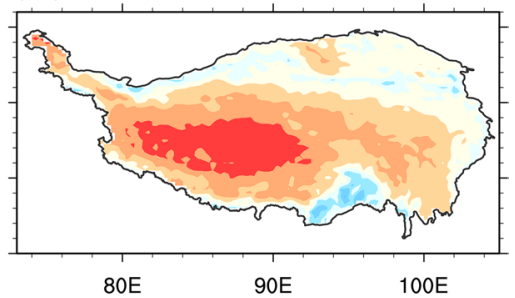

(b3) GTP

$31.5 \%$

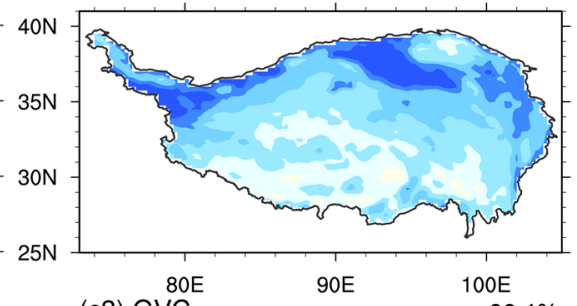

(c3) GVC

$30.1 \%$

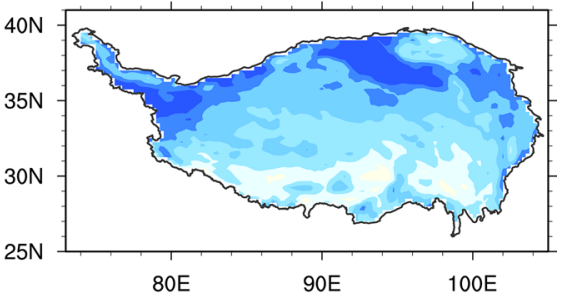

(d3) MTP $\quad 50.1 \%$

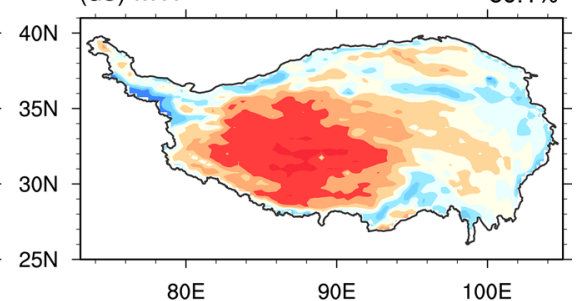

(e3) MVC $\quad 48.9 \%$

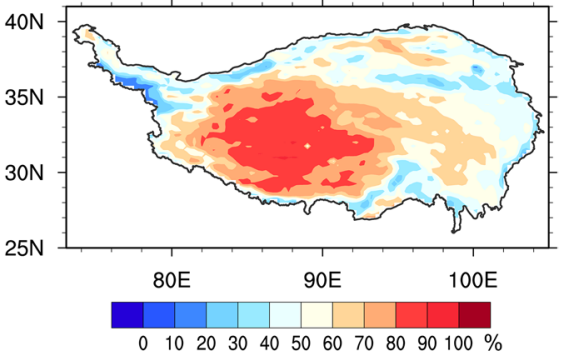

Fig. 4 Spatial distribution of a large-scale precipitation (LSP) and $\mathbf{b}$ convective precipitation (CP) from ERA5, and differences between the four simulations and ERA5, as well as c ratio of CP to total precipitation from ERA5 and the four simulations during the wet season.

convective precipitation ratio primarily depends on the horizontal and vertical structure of the radar signal (Kummerow et al. 2001; Kukulies et al. 2020). Hence, the CP contribution estimates are still associated with a large uncertainty which warrants further investigation.
The mean differences for simulations and ERA5 are labelled in the upper right corner of each panel. The dotted points denote the difference significant at the $95 \%$ confidence level

\subsubsection{Diurnal cycle of precipitation}

The diurnal cycle of precipitation was also analyzed to comprehend the model bias. Figure 5 shows the spatial distribution of diurnal peak time for maximum precipitation 
(a) Amount

(a1) GPM

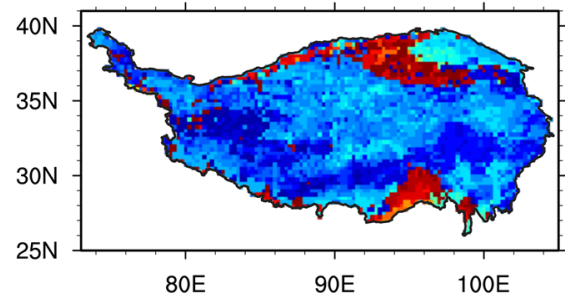

(b1) GTP

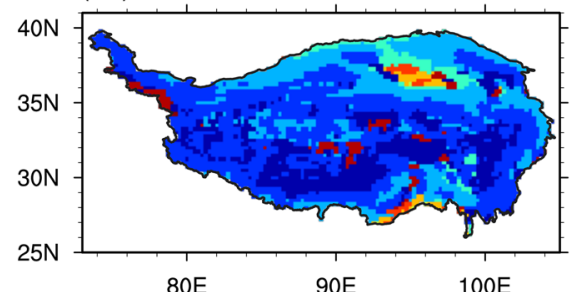

(c1) GVC

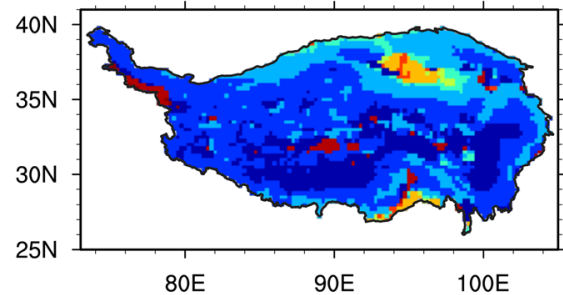

(d1) MTP

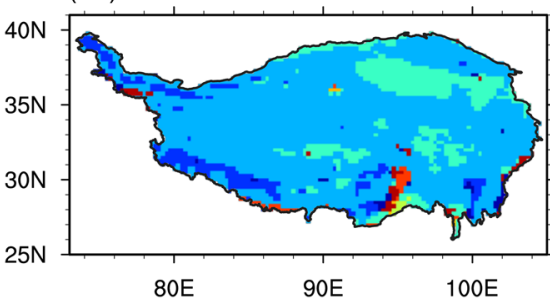

(e1) MVC

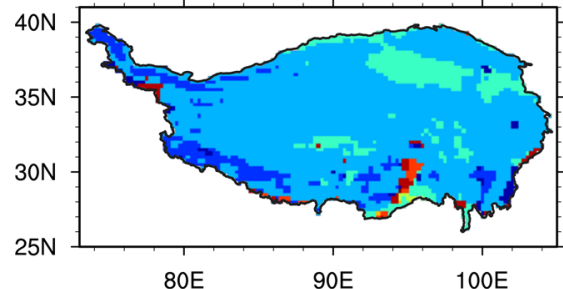

(b) Frequency

(a2) GPM

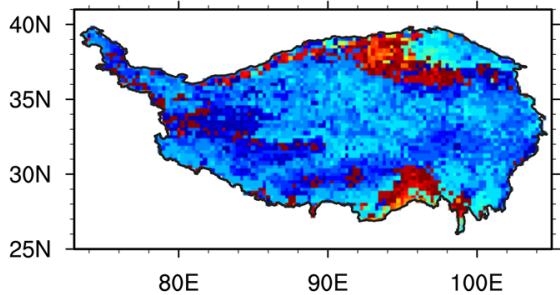

(b2) GTP

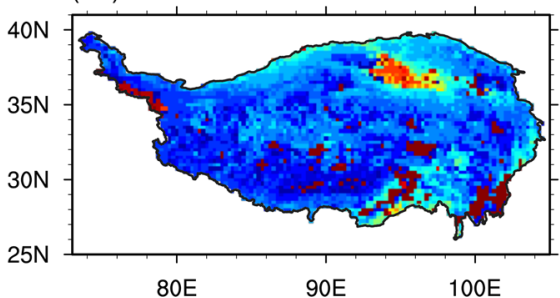

(c2) GVC

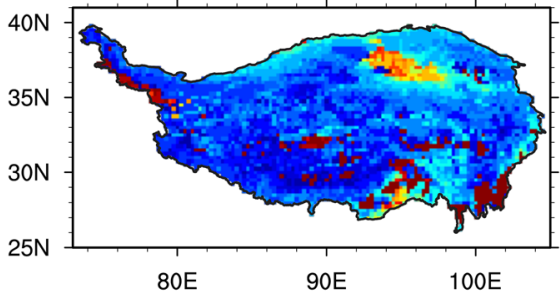

(d2) MTP

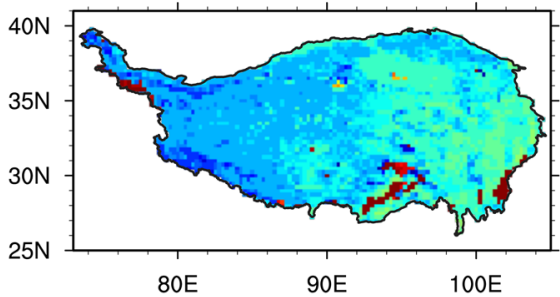

(e2) MVC

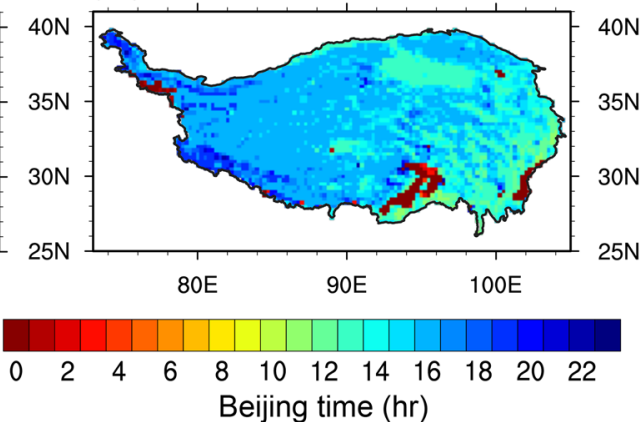

(c) Intensity

(a3) GPM

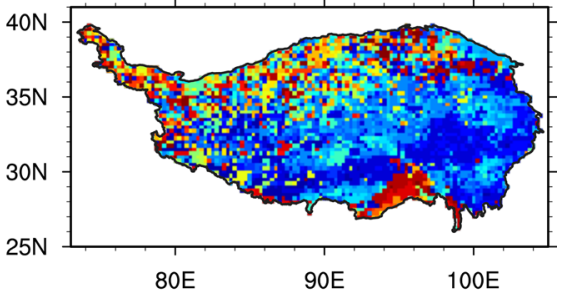

(b3) GTP

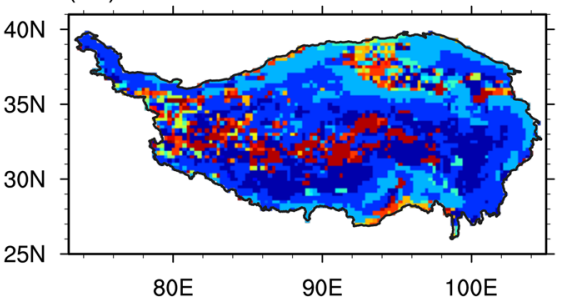

(c3) GVC

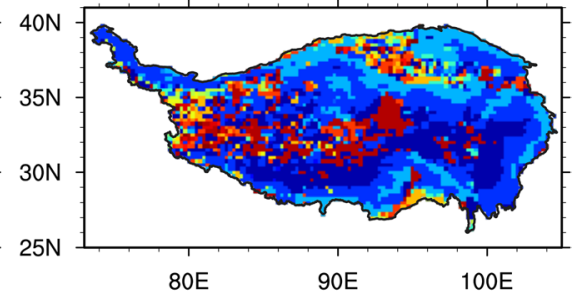

(d3) MTP

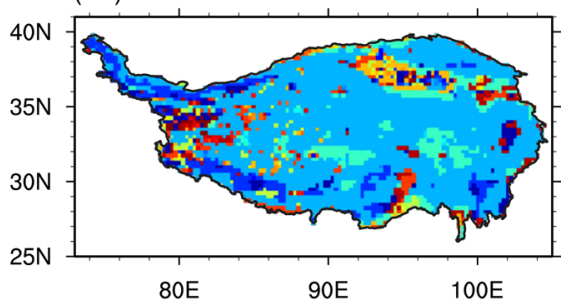

(e3) MVC

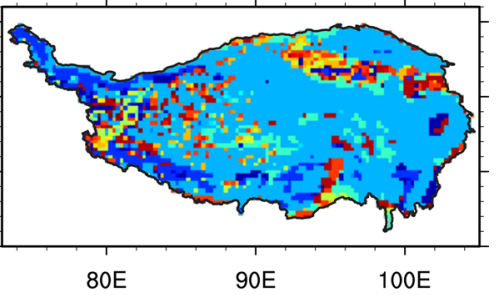

Fig. 5 Spatial distribution of diurnal peak time for maximum precipitation amount (a), frequency (b), and intensity (c) during the wet season from the GPM and the model simulations with different combination of schemes

in the wet season over the TP. The GPM data shows that the precipitation maximum mainly occurred in the late afternoon to early evening (17:00-20:00 Beijing time, the same thereafter) over most of the TP, and in the early morning (00:00-03:00) in the Qaidam Basin and the southern TP (Fig. 5a). Some areas such as the part of the western TP, the leeside of the Himalayas, and the Nyenchen Tanglha Mountains exhibited late-night peak of precipitation amount between 21:00 and 23:00. The spatial pattern is basically consistent with the results of previous studies (Kukulies et al. 2020; Ou et al. 2020) using the same satellite data but with a short time period. 
The RegCM4 simulations largely reproduced the main spatial pattern of diurnal peak time (17:00-20:00) for maximum precipitation (Fig. 5b1-e1). Besides, the simulations with the Grell scheme also reproduced the satellite observed late-night precipitation maximum between 21:00 and 23:00, but that's not the case for the simulations with the MIT scheme. In the dry Qaidam Basin and the wet southern TP, the model simulations yielded later peak times compared with the GPM data. For example, in the Qaidam Basin, the Grell scheme simulated the precipitation amount peak in the morning (08:00) and early afternoon (14:00), and the MIT scheme simulated the peak in the early afternoon. Overall, with respect to the Grell scheme, the MIT scheme produced more peaks in the afternoon but less at the night. The peak time of precipitation amount was less affected by different LSHSs, compared to that caused by changes in CPSs. Generally, the VIC scheme increased peaks during the night (20:00 and 23:00) and decreased peaks in the afternoon (14:00) relative to the TOP scheme.

The distributions of diurnal peak times of the most frequent and intense precipitation were also compared (Fig. 5a2-e3). Consistent with the previous study by Niu et al. (2020), the spatial patterns of the peak time of precipitation frequency resembled those of precipitation amount in both the GPM and model simulations, suggesting precipitation frequency may contribute greatly to the phase of the amount. A large difference existed for the simulations with the MIT scheme, which showed much earlier peaks in the frequency on the eastern TP than the GPM data and the results using the Grell scheme. With regard to intensity, the GPM data presented morning peaks on the northwestern TP and nighttime peaks on the southeastern TP. In the simulations with the Grell scheme, the western and central TP tended to exhibit an early morning peak, and peaks in other areas were altered from the afternoon to late night to afternoon when going from south to north. The experiments with the MIT scheme tended to simulate afternoon peaks over most of the TP and some patchy peaks in the morning and at night on the northwestern TP and Qaidam Basin. In general, there was a relatively large discrepancy in the spatial pattern of diurnal peaks in intensity between the model simulations and GPM data.

Figure 6 shows the regionally averaged diurnal variations of precipitation amount, frequency, and intensity from the model simulations and the GPM data. The GPM data showed a clear afternoon peak (18:00) over the entire TP, which could be dominated by the diurnal peak of precipitation frequency in the afternoon. The RegCM4 was able to well reproduce the diurnal cycles of precipitation amount and frequency, although some differences in phase and magnitude remained. The Grell scheme delayed the peaks for precipitation amount and frequency to about 1-2 h, while the MIT scheme advanced the afternoon peak by an hour. As for the intensity, the GPM data presented a low in the noon and a peak at late night, the model represented the low but simulated an earlier peak, especially in the simulations with the MIT scheme. Meanwhile, the MIT scheme reduced the precipitation intensity at the night through decreasing the precipitation amount. On the whole, the LSHS didn't seem to cause a remarkable change in the phrase of the diurnal cycle.

\section{Impacts of the CPS and LSHS on surface energy and water balance}

\subsection{Energy balance}

\subsubsection{Radiation balance components}

In Fig. 7 shows the differences in the radiation balance components between the four simulations and the ERA5 data over the entire TP. The four RegCM4 simulations produced unmistakably higher values of downward shortwave radiation than the ERA5, ranging from 12.9 to $37.1 \mathrm{~W} \mathrm{~m}^{-2}$, as a result of underestimated total cloud cover (Table 4). This is also true for the comparisons between the model simulations and the CERES data. The simulations with the Grell scheme produced higher values $\left(\sim 19 \mathrm{~W} \mathrm{~m}^{-2}\right)$ of downward
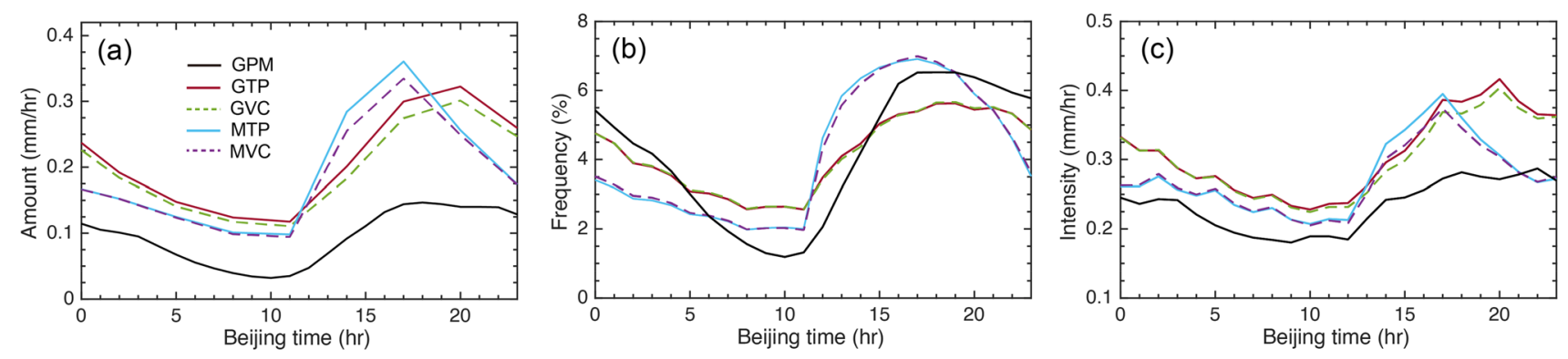

Fig. 6 Diurnal variations of precipitation amount (a), frequency (b), and intensity (c) during the wet season from the GPM and the model simulations with different combination of schemes over the TP 


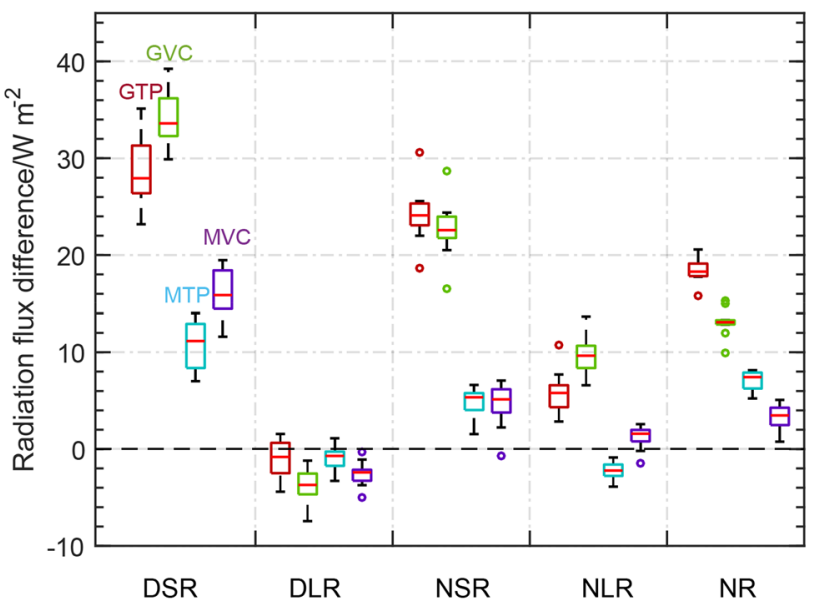

Fig. 7 Differences in radiation fluxes (DSR downward shortwave radiation, $D L R$ downward longwave radiation, NSR net shortwave radiation, $N L R$ net longwave radiation, and $N R$ net radiation) between the four experiments and ERA5 data. The red, green, blue, and purple boxes indicate the GTP, GVC, MTP, and MVC simulations, respectively. The horizontal lines in each boxplot represent the 11 years' minimum, 25th percentile, median, 75th percentile, and maximum, respectively, and open circles indicate outliers

shortwave radiation than those with the MIT scheme. As for the influence of the LSHS, the VIC scheme tended to increase downward shortwave radiation, by $\sim 6 \mathrm{~W} \mathrm{~m}^{-2}$. The differences in downward shortwave radiation relative to the reference data were in accordance with the differences in air temperature, with the highest downward shortwave radiation and air temperatures found in the GVC simulations and the lowest values in the MTP simulations. In comparison with the ERA5, the four simulations produced lower values of downward longwave radiation, ranging from -0.9 to $-3.9 \mathrm{~W} \mathrm{~m}^{-2}$. The MIT and TOP schemes tended to increase downward longwave radiation, thus, the MTP-simulated downward longwave radiation values were closest to the ERA5 data.

Surface albedo plays a key part in the shortwave radiation budget. Relative to the ERA5 data, the lower albedo simulated by the GTP yielded higher net shortwave radiation values (Table 4), and the highest albedo simulated by the MVC yielded the lowest net shortwave radiation. The RegCM4 model underestimated net shortwave radiation on the western TP and overestimated it on the rest of the TP (Fig. 8a). The MIT scheme significantly decreased the overestimation, and the VIC scheme could slightly reduce the overestimation. Thus, the MVC-simulated net shortwave radiation agreed well with the CERES data. The simulations with the VIC scheme produced higher values of net longwave radiation than the simulations with the TOP scheme, due to relatively high surface temperatures, while the simulations with the MIT scheme yielded lower values of net longwave radiation than those with the Grell scheme. Net longwave radiation simulated by the MVC model was also close to the CERES data. Taken together, the highest net shortwave radiation simulated by the GTP led to the highest net radiation, which could be reduced by the simulations with the MIT and VIC schemes; therefore, the MVC simulated the lowest net radiation, providing a closer fit to the ERA5 and CERES data. Relative to the CERES data, the model simulations presented lower net radiation on the western TP and higher values on the rest of the TP (Fig. 8c), which commendably supported the spatial pattern of air temperature biases (Fig. 2). The spatial pattern of net radiation
Table 4 A 11-year regional averaged surface radiation budget and water balance over the TP during wet season (MaySeptember) from the satellitederived data, ERA5, and four groups of experiment

\begin{tabular}{|c|c|c|c|c|c|c|}
\hline & $\begin{array}{l}\text { Satellite-derived } \\
\text { data }\end{array}$ & ERA5 & GTP & GVC & MTP & MVC \\
\hline Albedo & 0.20 & 0.26 & 0.25 & 0.27 & 0.27 & 0.29 \\
\hline Total cloud cover $/ \%$ & 69.5 & 67.8 & 59.5 & 57.9 & 57.7 & 56.8 \\
\hline $\mathrm{DSR} / \mathrm{W} \mathrm{m}^{-2}$ & 239.9 & 252.9 & 284.4 & 290.0 & 265.8 & 271.4 \\
\hline $\mathrm{NSR} / \mathrm{W} \mathrm{m}^{-2}$ & 192.1 & 188.4 & 212.7 & 211.1 & 193.2 & 192.9 \\
\hline $\mathrm{DLR} / \mathrm{W} \mathrm{m}^{-2}$ & 293.9 & 281.0 & 280.0 & 277.1 & 280.1 & 278.4 \\
\hline $\mathrm{NLR} / \mathrm{W} \mathrm{m}^{-2}$ & 80.6 & 79.3 & 85.2 & 89.0 & 77.1 & 80.5 \\
\hline $\mathrm{NR} / \mathrm{W} \mathrm{m}^{-2}$ & 111.5 & 109.1 & 127.5 & 122.2 & 116.2 & 112.4 \\
\hline $\mathrm{SHF} / \mathrm{W} \mathrm{m}^{-2}$ & - & 39.7 & 47.3 & 50.2 & 30.2 & 34.0 \\
\hline $\mathrm{LHF} / \mathrm{W} \mathrm{m}^{-2}$ & - & 59.1 & 68.6 & 60.4 & 74.5 & 66.8 \\
\hline Bowen ratio & - & 0.7 & 0.7 & 0.8 & 0.4 & 0.5 \\
\hline $\mathrm{ET} / \mathrm{mm} \mathrm{d}^{-1}$ & 2.5 & 2.0 & 2.4 & 2.1 & 2.6 & 2.4 \\
\hline $\mathrm{RO} / \mathrm{mm} \mathrm{d}^{-1}$ & - & 2.5 & 4.3 & 4.7 & 2.9 & 3.2 \\
\hline Storage $/ \mathrm{mm} \mathrm{d}^{-1}$ & - & 0.1 & 0.3 & -0.1 & 0.2 & -0.1 \\
\hline
\end{tabular}

- Indicates no available data

$D S R$ downward shortwave radiation, NSR net shortwave radiation, DLR downward longwave radiation, $N L R$ net longwave radiation, $N R$ net radiation, $S H F$ sensible heat flux, $L H F$ latent heat flux, ET evapotranspiration, $R O$ runoff 
(a) Net shortwave radiation (a1) GTP-CERES

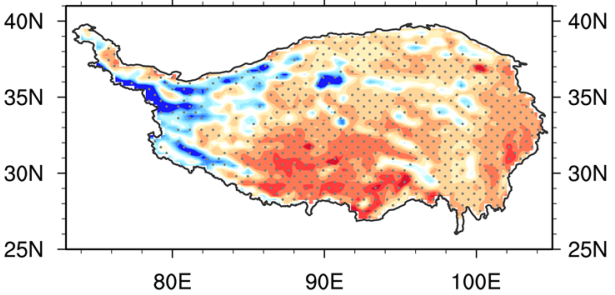

(b1) GVC-CERES

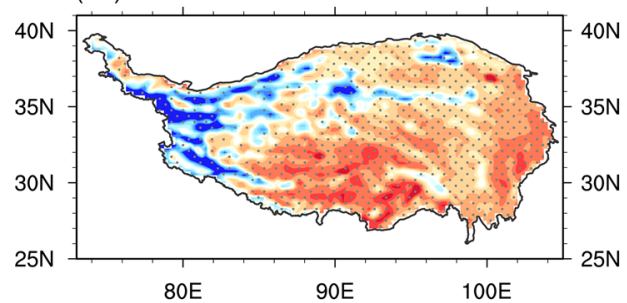
(c1) MTP-CERES

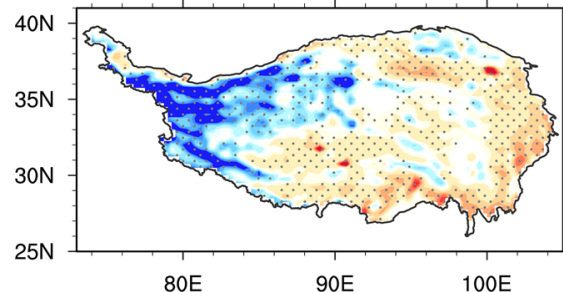
(d1) MVC-CERES

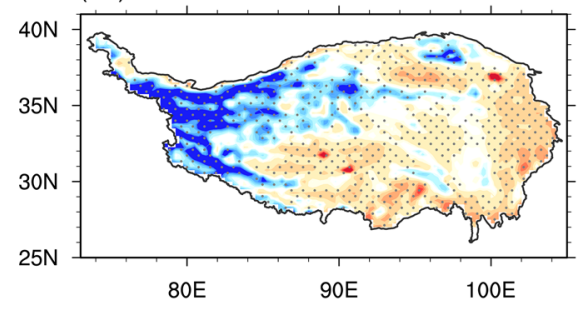

(b) Net longwave radiation (a2) GTP-CERES

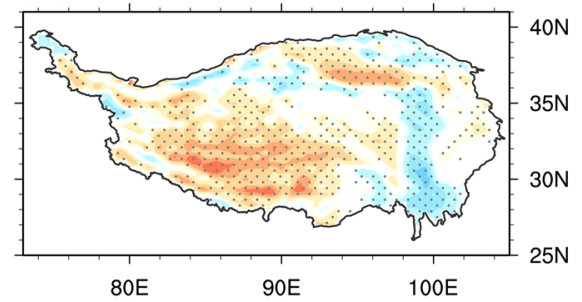
(b2) GVC-CERES

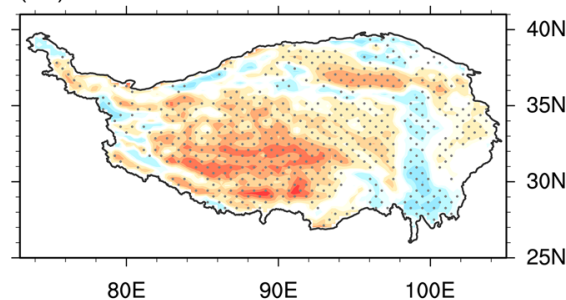
(c2) MTP-CERES
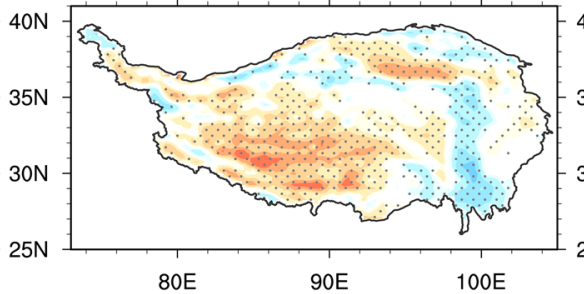
(d2) MVC-CERES
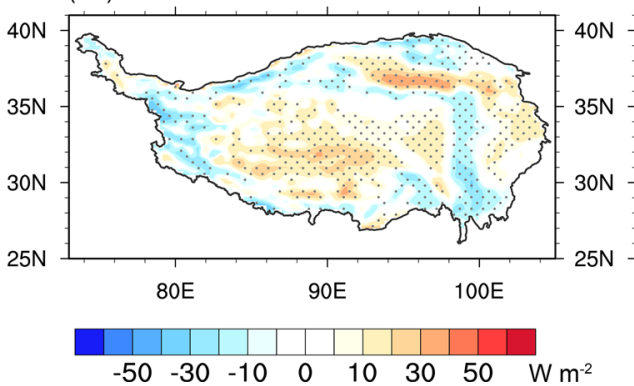

(c) Net radiation

(a3) GTP-CERES

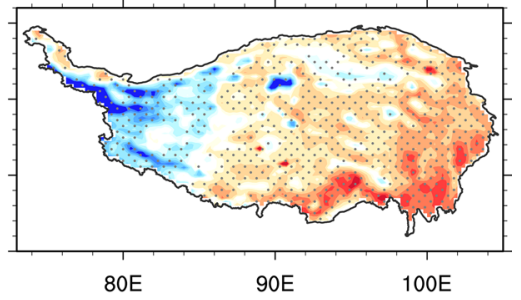

(b3) GVC-CERES

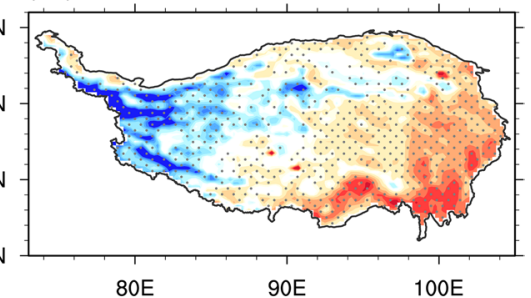

(c3) MTP-CERES

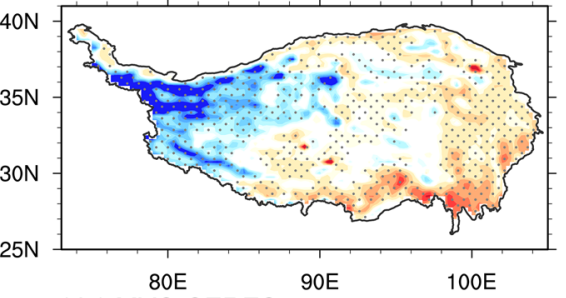

(d3) MVC-CERES

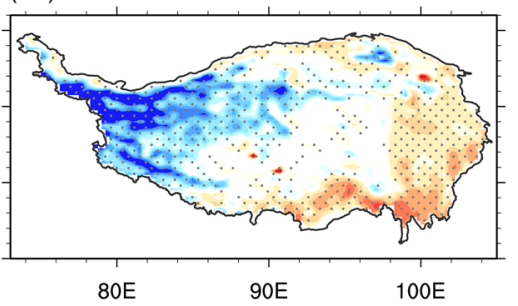

Fig. 8 Spatial distribution of differences in surface a net shortwave radiation, $\mathbf{b}$ net longwave radiation, and $\mathbf{c}$ net radiation between the four simulations and CERES during the wet season. The dotted points denote the difference significant at the $95 \%$ confidence level

was dominated by net shortwave radiation because of their similar patterns.

\subsubsection{Surface heat fluxes and ground heat source}

The spatial distribution of the surface heat flux differences between the model simulations and ERA5 data is shown in Fig. 9. The GTP simulated a significantly higher sensible heat flux over a large area of the TP and higher latent heat flux over the eastern TP compared with the ERA5 data. Configured with the MIT scheme, the simulations clearly reduced sensible heat flux relative to the simulations with the Grell scheme, but enhanced latent heat flux on the western TP. When precipitation increases and surface soil becomes moist, latent heat flux has a more dominant role than sensible heat flux (Table 4). The decreases in sensible heat flux are greater than the increases in latent heat flux, causing decreases in the Bowen ratio (sensible heat flux/ latent heat flux) in the simulations with the MIT scheme, suggesting a greater portion of the available energy at the surface is transferred to the atmosphere through latent heat flux. The GVC and MVC simulated significantly larger values of sensible heat flux on the central TP and smaller values of latent heat flux on the western TP, compared to the GTP and MTP simulations, respectively. This means that the induced decrease in latent heat flux by the VIC scheme overwhelmed the increase in sensible heat flux, thereby increasing the Bowen ratio. This is consistent with the study of Anwar et al. (2019). Besides, air temperature is also dependent upon the partition of net radiation between sensible and 
(a) Sensible heat flux

(a1) GTP-ERA5

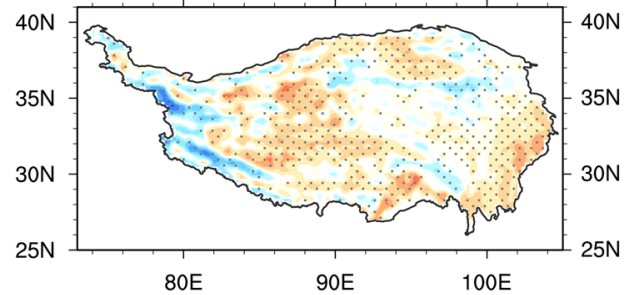

(b1) GVC-ERA5

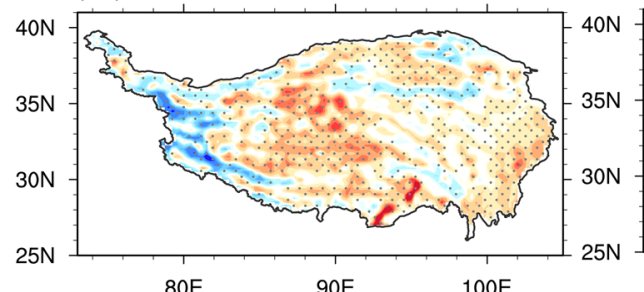

(c1) MTP-ERA5

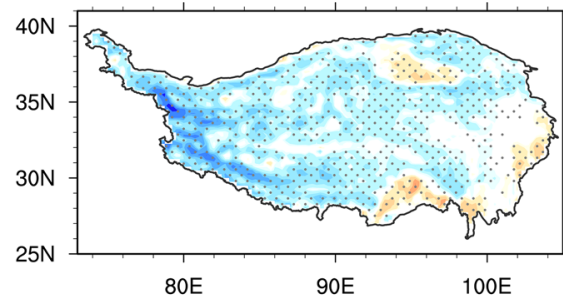

(d1) MVC-ERA5

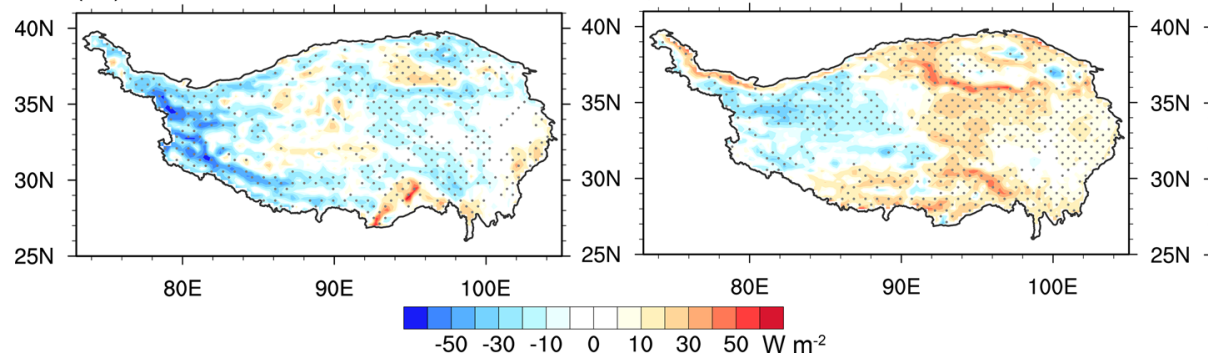

(b) Latent heat flux

(a2) GTP-ERA5
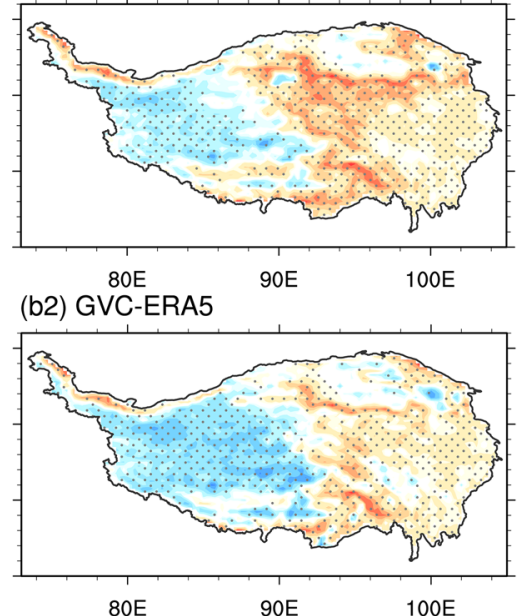

(c2) MTP-ERA5
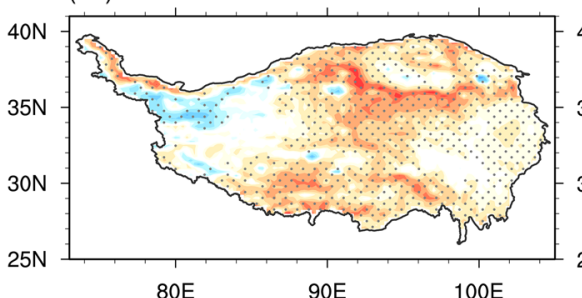

(d2) MVC-ERA5 (b2) GVC-ERA5 (c) Ground heat source

(a3) GTP-ERA5

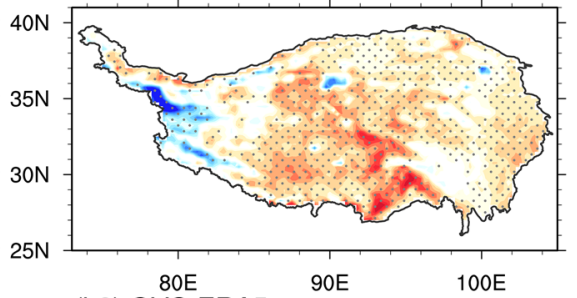

(b3) GVC-ERA5

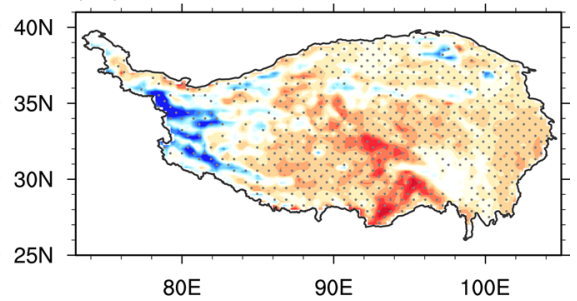

(c3) MTP-ERA5

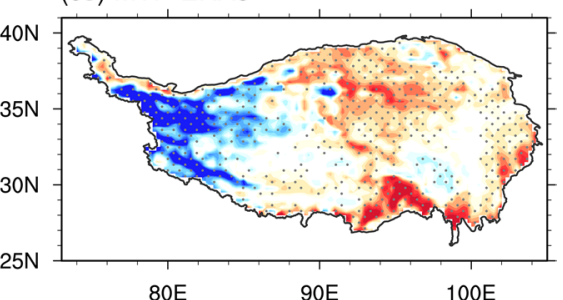

(d3) MVC-ERA5

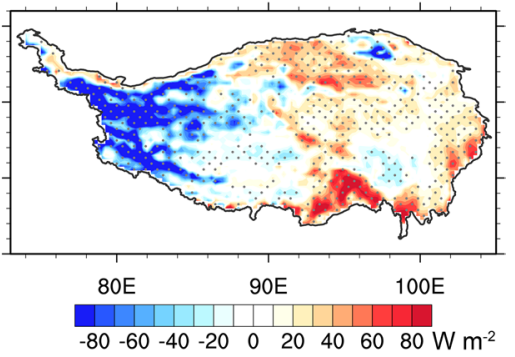

Fig. 9 As Fig. 4a, but for sensible and latent heat fluxes and ground heat source

latent heat fluxes. The distinctly different land cover types between the western (desert and semi-desert) and eastern TP (grass) (Fig. 1b) may play an important role in soil moisture retention and surface energy partition. The wetter soil on the eastern TP (shown in Fig. 10b) tends to generate higher latent heat flux (Fig. 9b) due to stronger net radiation. Therefore, the warm bias of air temperature on the eastern TP is likely caused by excessive net radiation and subsequent latent heating associated with moist soils.

Taken together with surface heat fluxes and surface effective radiation (Ye and Gao 1979), the ground heat source (GHS) is obtained (Fig. 9c). The GHS is of great importance for ground heating the atmosphere, in that its three components comprise the main energy source of the lower atmosphere. Since the air density over the TP is less than its surroundings, the atmospheric heating is more efficient.
The heating over the TP, known as the air-pump, has been recognized as not only strengthening the Asian monsoon circulation (Ye and Gao 1979; Duan et al. 2012; Wu et al. 2015) but also inducing local convective activity (Yang et al. 2004; Wang et al. 2016). Compared with the ERA5 data, the GTP overestimated the GHS over most of the TP but underestimated it over part of the western TP. These spatial patterns are similar to those of air temperature, indicating that the temperature bias can be ascribed to the bias in GHS. The MIT scheme appeared to decrease the strength of the GHS over almost the entire TP, thus generating a much weaker GHS than the GTP simulation. Similarly, the simulations with the VIC scheme generated an overall weaker GHS than those with the TOP scheme, albeit displaying some positive values. Among the four simulations, the MVC simulation yielded the weakest GHS, which was slightly higher than 
Fig. 10 Spatial distribution of soil moisture difference for a surface layer $(0-5 \mathrm{~cm})$ and $\mathbf{b}$ top 1 -m soils (vertically averaged from surface to 1-m depth) between the four simulations and reference data (a1-a4 for AMSR, b1-b4 for ERA5) during the wet season. The mean differences (\%) are labelled in the upper right corner of each panel. The dotted points denote the difference significant at the 95\% confidence level (a) $0-5 \mathrm{~cm}$ soil moisture
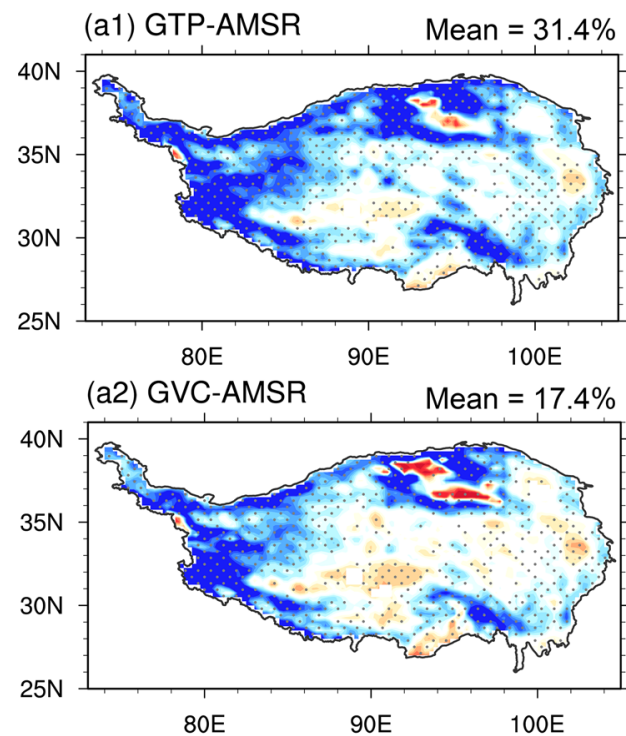

(a3) MTP-AMSR
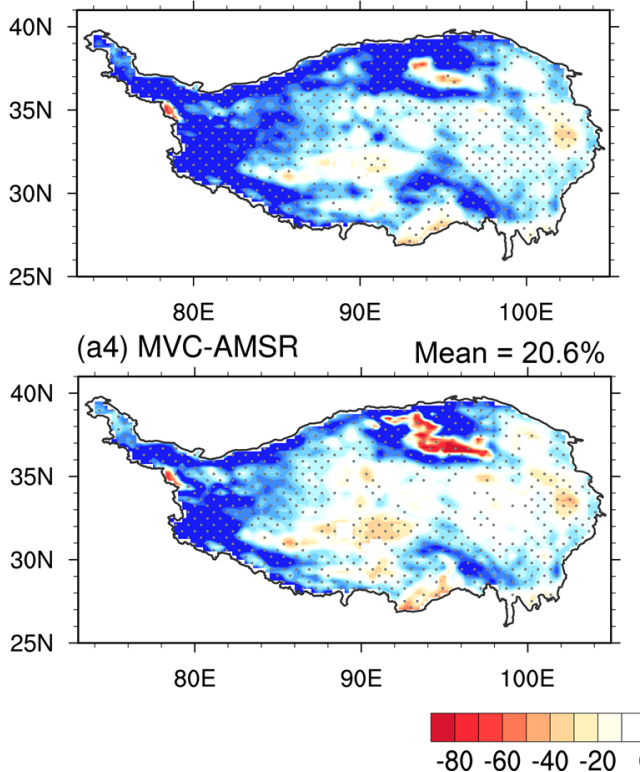

$\begin{array}{llllllllll}-80 & -60 & -40 & -20 & 0 & 20 & 40 & 60 & 80 & \%\end{array}$ (b) 0-1 $\mathrm{m}$ soil moisture

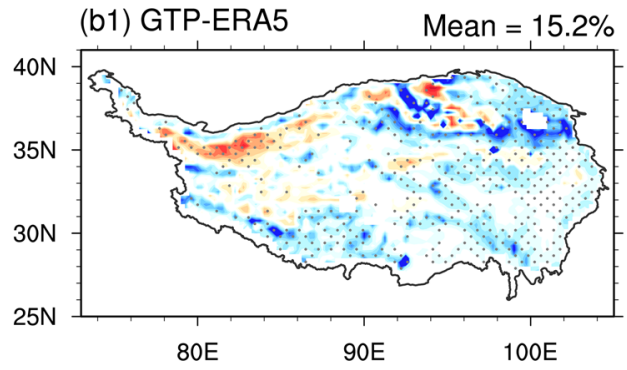

(b2) GVC-ERA5 Mean $=-5.6 \%$

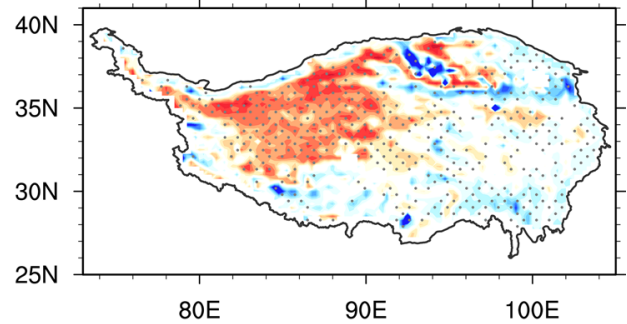

(b3) MTP-ERA5 Mean $=25.9 \%$

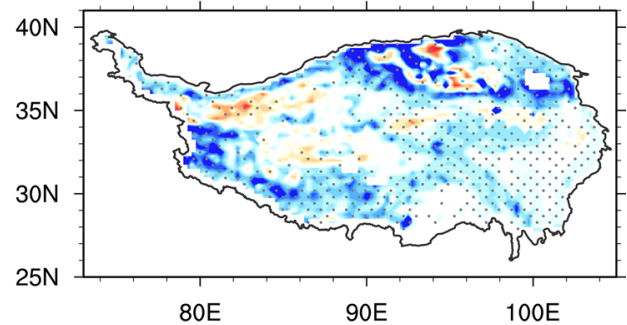

(b4) MVC-ERA5 Mean $=-2.3 \%$

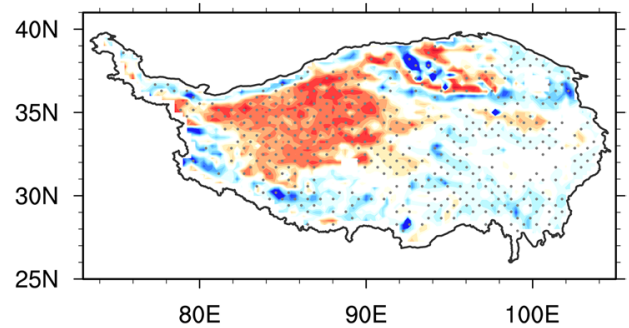

but closest to the ERA5 data, while the GTP simulation produced the strongest GHS.

\subsection{Water budget}

\subsubsection{Soil moisture}

In general, soil moisture is largely affected by precipitation and gradually decreases from southeast to northwest over the TP. The spatial distribution of the surface soil moisture $(0-5 \mathrm{~cm})$ difference between the four model simulations and satellite data (AMSR) exhibited a significantly wet bias along the TP periphery except in Qaidam Basin (Fig. 10a). The RegCM4 model with the MIT scheme tended to produce wetter surface soil layers than that with the Grell scheme, by $3.2-5.7 \%$, and the model with VIC scheme simulated surface soil $14-16.5 \%$ drier compared to that with TOP scheme, especially in the TP hinterland. Soil moisture in the ERA5 data has been validated with in-situ observations on the TP and was shown to capture the spatial characteristics (Cheng et al. 2019). The spatial distribution of the 0-100 cm soil moisture difference between the GTP simulation and ERA5 data exhibited a significantly wet bias on the TP, except in the Qaidam Basin and Qiangtang Plateau (Fig. 10b1), largely following that of the precipitation difference. The MTP reduced the underestimation in the Kunlun Mountains and Qaidam Basin and the overestimation on the southeastern TP but aggravated the overestimation on the 
southwestern and western TP, therefore generating higher soil moisture than the ERA5 data (by $\sim 25.9 \%$ ) and the GTP simulation (by $\sim 10.7 \%$ ). The comparisons between the simulations with the VIC scheme and the ERA5 data revealed that there were significant negative values on the northwestern TP and patchy positive values in the rest of the TP, with the overall simulated TP soil moisture 2.3-5.6\% drier than the ERA5 data. The VIC scheme substantially reduced the wet biases of soil moisture generated by the GTP and MTP but aggravated the dry bias on the northwestern TP. The soil moisture difference between the MVC and GVC simulations was smaller than that between the MTP and GTP simulations, indicating that implementing the VIC scheme into the model could reduce the soil moisture difference caused by different CPSs. Also, the soil moisture difference between the two runoff schemes was larger than between the two cumulus schemes. Overall, the GVC and MVC simulated soil moisture contents that better agreed with the reference data (AMSR and ERA5). Such results indicated the role of the land surface processes (runoff in this study) for constraining soil moisture against the reference dataset.

The soil moisture changes generated by different CPSs were significantly different than those generated by LSHSs. This is probably related to the spatial distribution of soil moisture and the different ways that CPSs and LSHSs influence precipitation. CPS-induced precipitation differences mainly occurred on the southeastern TP, where soils are generally wet, while LSHS-induced precipitation changes appeared on the central-western TP, where soil moisture is relatively low and more variable. Therefore, a slight change in precipitation on the central-western TP can trigger a more rapid soil moisture response.

\subsubsection{Other water budget components}

Soil moisture feeds evaporation through water recycling. The model-simulated evapotranspiration (ET) was roughly in agreement with the spatial pattern reflected by the satellitederived data $(\mathrm{SCOR}>0.43)$. The regionally-averaged values simulated by RegCM4 were close to the satellite-derived data (Table 4), although ET remained biased low in all simulations except for the MTP simulation. While higher values of ET, approximately $0.1-0.6 \mathrm{~mm} \mathrm{day}^{-1}$, were simulated by the four simulations relative to the ERA5 data (Fig. 11). Configured with the same CPS, such as the Grell scheme, the model with the TOP scheme tended to simulate a larger ET than with the VIC scheme because the higher infiltration rate simulated by the TOP scheme allows more water to infiltrate the soil surface than the VIC scheme (Fig. S1). When configured with the same LSHS, corresponding to wet soils, the MIT scheme appeared to simulate higher ET than the Grell scheme. The differences in ET between model simulations were in accordance with the differences in latent

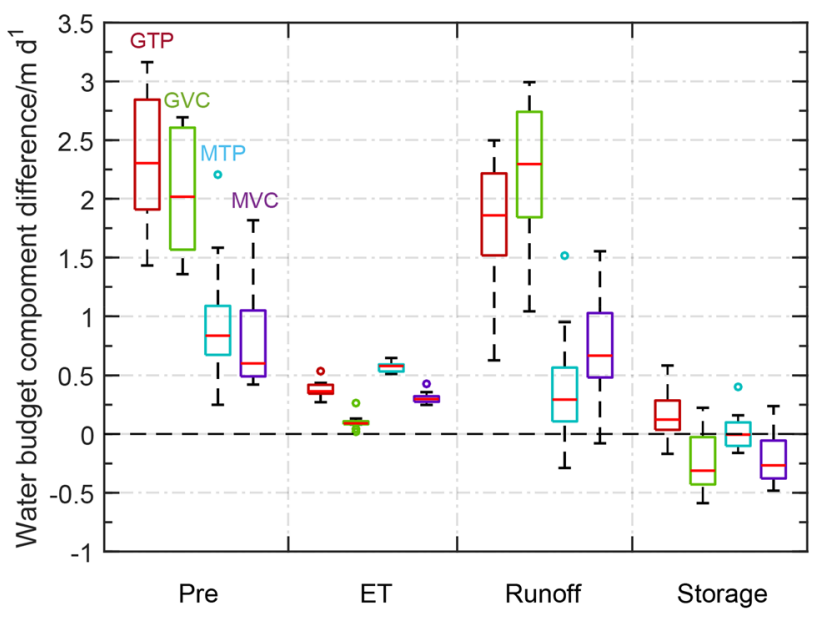

Fig. 11 As Fig. 7, but for surface water budget components: precipitation (Pre), evapotranspiration (ET), total runoff (Runoff), and storage

heat flux. This suggests that high soil moisture simulated by the TOP scheme, particularly in the case of the MTP simulations, fed more ET and latent heat flux, facilitating local precipitation, as indicated by the high ET coefficient $(0.46$, ET/precipitation) and relative humidity at $2 \mathrm{~m}$ especially on the western TP (Fig. S2). Meanwhile, compared with the simulations with the TOP scheme, the drier soils generated by the simulations with the VIC scheme yielded higher sensible heat flux and lower latent heat flux (ET), resulting in less moisture transferred to the atmosphere (Fig. S2).

There was a large interannual variation in the total runoff, as indicated by the great ranges of runoff difference. The total runoff values produced by the four simulations were appreciably higher than that of the ERA5, ranging from 0.4 to $2.2 \mathrm{~mm}$ day $^{-1}$. The MIT scheme decreased the overestimation of total runoff by reducing precipitation. The VIC scheme tended to simulate a higher runoff than the TOP scheme, possibly because the soil water produced by the VIC scheme was more likely to generate runoff to drain away. Anwar et al. (2019) indicated that the VIC model simulated low soil infiltration rates in Africa, leading to more soil water accumulating on the soil surface and forming surface runoff. For the TP, however, compared to the TOP scheme, the VIC scheme simulated less surface runoff (figure not shown), and more soil water was simulated to transmit through deep soil layers to enhance total runoff, which is probably linked to the extensively developed frozen soil (Niu and Yang 2006; Yang et al. 2019). Because the warm surface produced by the VIC scheme is conducive to the thawing of frozen soil, this increases soil water permeability (Fig. S3), which would enhance total runoff. In addition, other land-surface factors, such as soil texture, vegetation, and topography, may also play a role. Total runoff accounted for the majority of the output of the water budget, 
with the runoff coefficient (runoff/precipitation) reaching 0.7 in the GVC simulations. High runoff means low soil water storage. The soil water storage values simulated by the GVC and MVC were smaller than the ERA5 data, as well as the GTP and MTP simulations, resulting in drier soil conditions, especially on the western TP.

\section{Moisture flux transport and vertical motion}

In order to obtain deep insight into the direct sources of differential precipitation simulations, the large-scale moisture flux transport (MFT) and vertical motions were further analyzed. Due to the aforementioned diverse strength of the GHS, the large-scale MFT moisture flux $(\vec{Q})$ and moisture flux convergence (MFC) from the four simulations and the ERA5 data were expected to exhibit different features and to account for regional precipitation. The vertically-integrated moisture flux $\vec{Q}$ in the atmosphere and the MFC are expressed as follows:

$\vec{Q}=\frac{1}{g} \int_{300}^{p_{s}} q \vec{V} d p$

$M F C=\frac{1}{g} \int_{300}^{p_{s}} \nabla(q \vec{V}) d p$

where $g$ is the acceleration of gravity, $q$ is the specific humidity, $\vec{V}$ is the horizontal wind vector, $p$ is the pressure, $p_{s}$ is the surface pressure, and $\nabla$ is the horizontal gradient operator. The pressure of top layer was set to $300 \mathrm{hPa}$ because the majority of water vapor is within the surface to $300 \mathrm{hPa}$ (Feng and Zhou 2012; Zhou et al. 2019). Figure $12 \mathrm{a}-\mathrm{d}$ present the spatial distributions of $\vec{Q}$ and MFC from the ERA5 data and three model simulations (since the MVC simulation was similar to the MTP simulation, it is not shown) during the wet season. Due to the strong impact of the monsoon circulation, the ERA5 data and RegCM4 simulations all exhibited MFT by southwesterlies over the southeastern TP. Compared to the ERA5 data, however, the simulations, especially with the Grell scheme, produced stronger southwesterlies and MFC on the southeastern TP, contributing to the overestimations of LSP and precipitation. In contrast, the MIT scheme could substantially decrease these due to its apparently weak GHS. As such, CPSs can trigger large-scale MFT to impact precipitation by regulating the intensity of the GHS.

Based on the differences in the MFT and humidity in the lower free atmosphere $(500 \mathrm{hPa})$, the GTP simulated an anomalous cyclonic circulation over the southern TP and an anticyclonic circulation over the western TP relative to the ERA5 data (Fig. 12e), which were beneficial for increasing precipitation on the southeastern TP and decreasing precipitation on the western TP, respectively (Fig. 3c1). Meanwhile, the MTP did not simulate the cyclonic circulation and humid air (Fig. 12f). The comparison between the MTP and GTP simulations further suggests that the MIT scheme could eliminate the anomalous cyclonic circulation, helping to reduce atmospheric moisture and LSP on the TP (Fig. 4d1). In terms of the influence due to the LSHS, the GVC (MVC) simulated an anticyclonic circulation over the entire TP, indicating a weaker MFC and less MFT towards the TP relative to the GTP (MTP) simulation. We also noticed that the anomalous cyclonic circulation simulated by the GTP could lead to overestimated CP on the southeastern TP since the occurrence of $\mathrm{CP}$ requires moisture and upward motion, which can be supplied by the circulation. Therefore, besides its main contribution to LSP, MFC could also influence CP by lifting air and supplying moisture.

To connect the differences in $\mathrm{CP}$ with the dynamic field, we examined moisture static energy (MSE) over the TP. MSE has been widely used to investigate the instability of the atmosphere associated with precipitation $(\mathrm{Pu}$ and $\mathrm{Cook}$ 2012; Niu et al. 2020). It is expressed as

$\mathrm{MSE}=c_{p} T+L_{v} q+g z$,

where $c_{p}$ and $L_{v}$ denote the specific heat of air and latent heat of water vaporization, respectively; $g$ is the gravitational acceleration; and $T, q$, and $z$ represent air temperature, specific humidity, and geopotential height, respectively. A stable atmosphere generally displays increasing MSE with altitude. A high value of MSE at low levels destabilizes the atmosphere (Neupane and Cook 2013). Negative slopes of the anomalous MSE profiles (Fig. 13), especially below $500 \mathrm{hPa}$, indicate that the low-level atmosphere was more unstable in the four simulations than the ERA5 data. The simulations with the MIT scheme had steeper MSE gradients than those with the Grell scheme, indicating that the low-level atmosphere in the simulations with the Grell scheme was more stable than in the simulations with the MIT scheme. It also can be seen in the cross-section of vertical motion that the vertical velocity values simulated by the MTP and MVC between $28^{\circ} \mathrm{N}$ and $31^{\circ} \mathrm{N}$ were more negative (Fig. 14). The increased instability was more related to the thermal term $c_{p} T$ since the negative values of the moisture term $L_{v} q$ between 600 and $400 \mathrm{hPa}$ tended to stabilize the low troposphere, and changes in the geopotential term $g z$ were negligible. Above $500 \mathrm{hPa}$, the simulations with the Grell scheme produced positive slopes of the anomalous MSE, acting to stabilize the mid- and high-troposphere, which probably contributed to the lower CP in the GTP and GVC simulations relative to the ERA5 data. Between 500 and $300 \mathrm{hPa}$, in association with decreases in $c_{p} T$, the anomalous MSEs in the MTP and MVC simulations 
Fig. 12 Spatial distribution of vertically integrated moisture flux $\left(\mathrm{kg} \mathrm{m}^{-1} \mathrm{~s}^{-1}\right)$ and convergence (MFC: $10^{-2} \mathrm{~kg} \mathrm{~m}^{-2} \mathrm{~s}^{-1}$ ) from a the ERA5 and the three simulations (b GTP, c GVC, and d MIT) over the TP, as well as the differences in water vapor transport $\left(10^{-5} \mathrm{~g} \mathrm{~kg}^{-1} \mathrm{~s}^{-1}\right)$ and specific humidity $\left(\mathrm{g} \mathrm{kg}^{-1}\right)$ at $500 \mathrm{hPa}$ height from e GTPERA5, f MTP - ERA5, g MTPGTP, and $\mathbf{h}$ GVC-GTP (a) ERA5

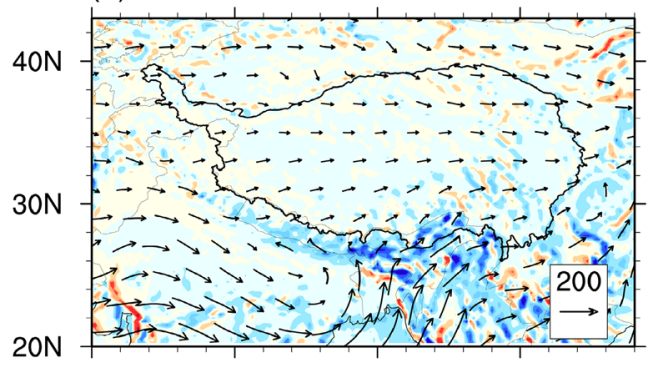

(b) GTP

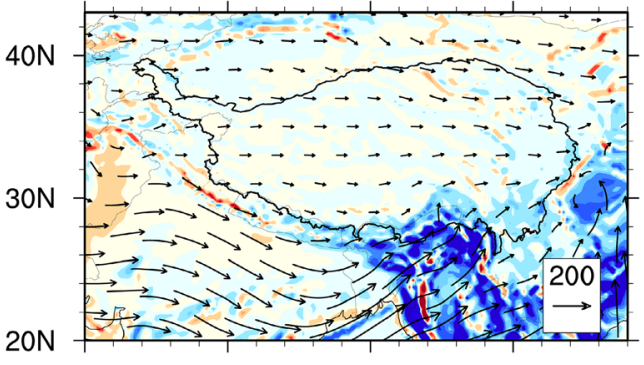

(c) GVC

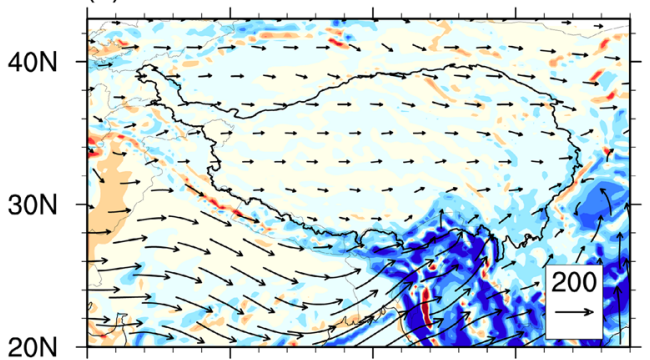

(d) MTP

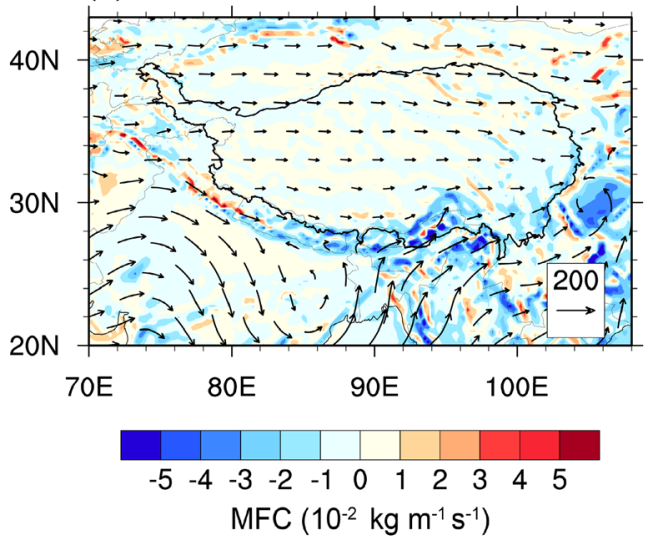

(e) GTP-ERA5

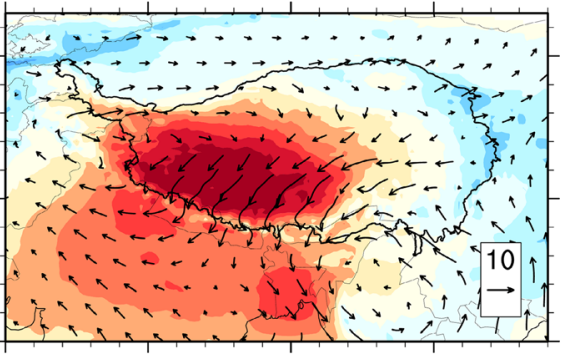

(f) MTP-ERA5

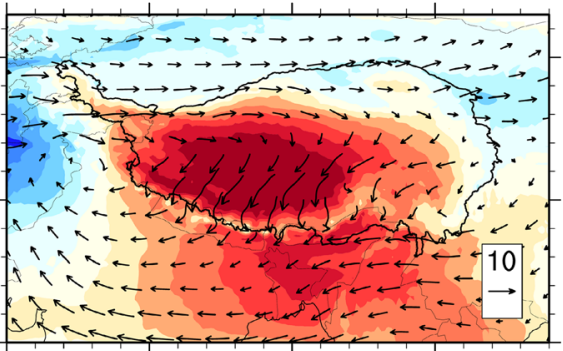

(g) MTP-GTP

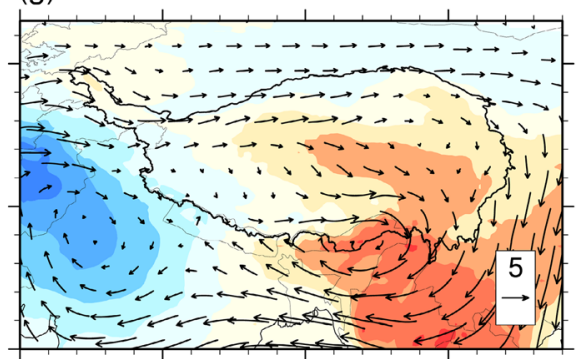

(h) GVC-GTP

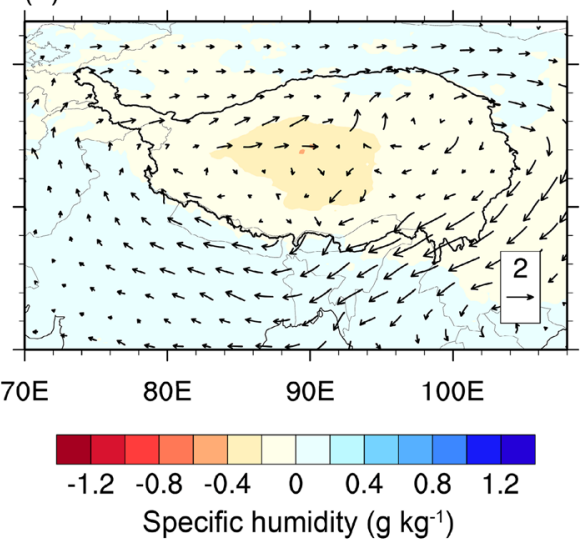

exhibited some negative gradients, which continuously increased instability, while above $300 \mathrm{hPa}$ the anomalous MSE gradients became positive, suggesting that deep convection was suppressed. Consequently, the MTP and MVC simulations displayed stronger vertical convection between 600 and $300 \mathrm{hPa}$ than the ERA5 data and the GTP and GVC simulations.

Below $500 \mathrm{hPa}$, in association with decreases in the moisture term $L_{v} q$, the anomalous MSE caused by the VIC scheme had relatively small gradients compared to those caused by the TOP scheme, indicating that shallow convection was suppressed by the VIC scheme. Consistent with this, a drier atmosphere was clearly found in the GVC and MVC simulations than in the GTP and MTP simulations (Fig. 14). As a result, the GVC and MVC simulated low amounts of CP (Fig. 4b). The ERA5 data showed broader negative values above $400 \mathrm{hPa}$ between 25 and $34^{\circ} \mathrm{N}$ and $85-100^{\circ} \mathrm{E}$, indicating stronger deep convection than the four simulations. Nevertheless, atmospheric humidity in the upper troposphere, which is a moisture-limited area, exerted 
Fig. 13 Profiles of difference in a moisture static energy (MSE), b temperature component $\left(c_{p} T\right)$, and $\mathbf{c}$ moisture component $\left(L_{v} q\right)$ $\left(10^{3} \mathrm{~m}^{2} \mathrm{~s}^{-2}\right)$ between the four simulations and ERA5 averaged over the TP during the wet season (a) $\triangle \mathrm{MSE}$

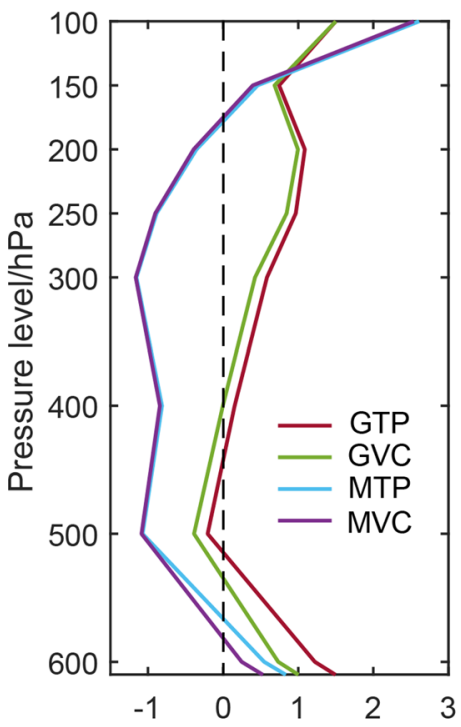

(b) $\Delta c_{p} T$

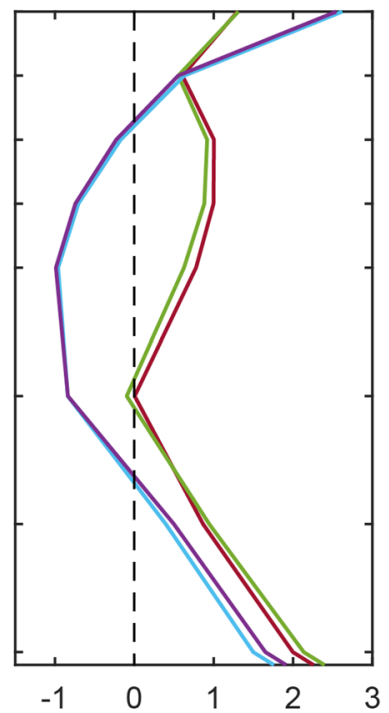

(c) $\Delta \mathrm{L}_{\mathrm{v}} \mathrm{q}$

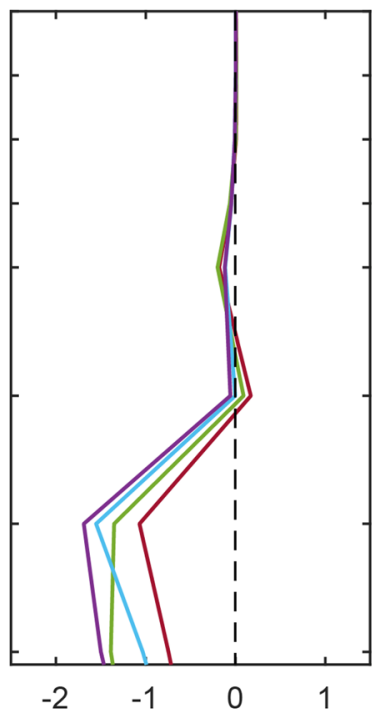

(a) ERA5
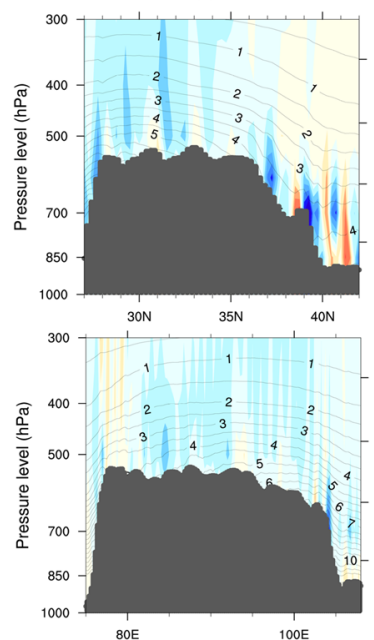

(b) GTP

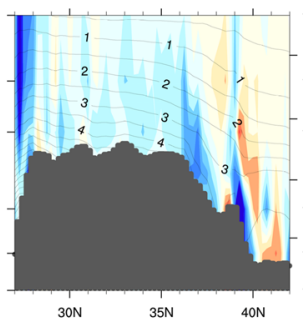

(c) GVC

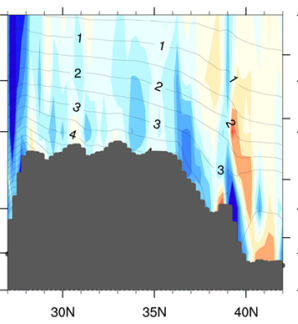

(d) MTP

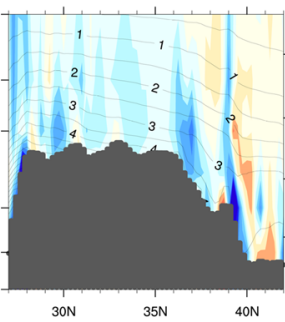

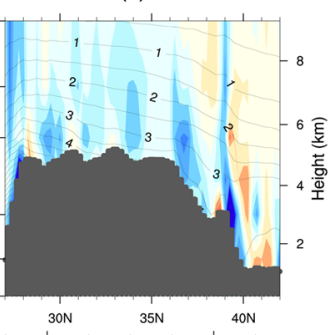

(e) MVC
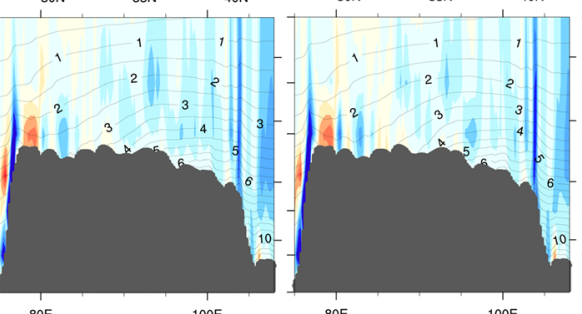

$80 \mathrm{E}$

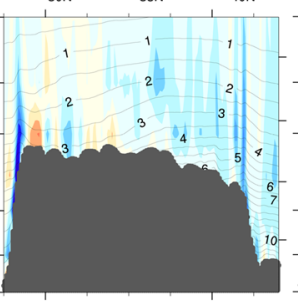

$80 \mathrm{E}$

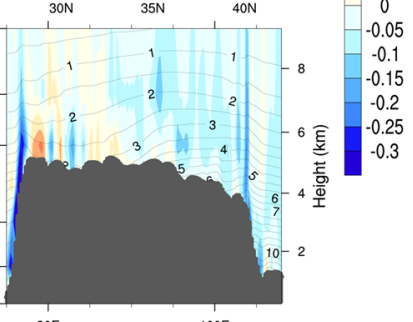

Fig. 14 Cross section of vertical motion ( $\mathrm{Pa} \mathrm{s}^{-1}$, contour filling) and specific humidity $\left(\mathrm{g} \mathrm{kg}^{-1}\right.$, contour line) along $92^{\circ} \mathrm{E}$ (upper) and along $32.5^{\circ} \mathrm{N}$ (lower) from the ERA5 data and the four simulations in the wet season

a limited impact on CP. Note that Fig. 14 also shows robust vertical motions in the windward slopes around $27^{\circ} \mathrm{N}$ and $75-80^{\circ} \mathrm{E}$ in the GTP and GVC simulations, which were largely caused by the large-scale MFT and MFC mentioned above. The vertical motions were not that prominent in the MTP and MVC simulations due to a lack of anomalous cyclonic circulation.

The GHS was mainly used to account for the wet season precipitation. Replacing the Grell scheme with the MIT scheme could significantly reduce the intensity of the GHS, thereby reducing the overestimation of precipitation by decreasing atmospheric moisture transport and moisture convergence. The MVC-simulated GHS and precipitation were in close agreement with the ERA5 data. As pointed out by Ou et al. (2020), the ERA5 has overestimated precipitation over the TP in comparison with both satellite and in-situ observations. A similar conclusion can be drawn in this study compared with the GPM data (Fig. 3), indicating the possibility that both the MVC and ERA5 have stronger GHSs than the observations that are rarely obtained. Here, we designed four groups of sensitivity experiments with different CPSs and LSHSs in order to decrease the strength of the GHS. Compared to ERA5, GHS remained overestimated by RegCM4 regardless of configuring with the CPS and LSHS, which could be attributed to the overestimated net radiation and latent heat flux. More specifically, compared 
with the CERES satellite data and ERA5, downward shortwave radiation was overestimated by RegCM4 because of the lower total cloud cover. Although surface albedo bias remained to be high, net shortwave radiation was also higher in the model simulations than the reference data (Fig. 8a), indicating solar heating contributed more to higher surface net radiation with reference to the ERA5 data. Subsequently, higher values of latent heat flux associated with wetter soil were in the model simulations than in the ERA5 data, especially on the eastern TP. Consequently, the intensities of GHS in the model simulations were contributed greatly by the overestimated net radiation and latent heat flux. A previous study adopted a soil thermal conductivity scheme associated with frozen ground to represent a small soil thermal conductivity and to diminish GHS intensity (Wang et al. 2016). Therefore, modifying the GHS by revising the model physics can be an effective way to improve precipitation simulation.

The mode resolution $(20 \mathrm{~km})$ in the study may not be fine enough to adequately resolve the steep terrain in the southeastern TP and associated small-scale processes. As Lin et al. (2018) reported that finer resolution $(10 \mathrm{~km}$, especially $2 \mathrm{~km}$ ) is able to decrease the wet bias by better resolving orographic drag over a complex terrain and small-scale processes. Some studies argued that climate models even with a mesh size of $10 \mathrm{~km}$ cannot resolve some processes that operate on the model grid and therefore have to be parameterized (Prein et al. 2015 and references therein). However, these parameterizations are major error sources of model simulations. Therefore, high resolution (a few km scale) climate simulation, especially the convection permitting modeling, is expected to be a promising approach to improve the model simulation ability over the areas with steep terrain. A recent CORDEX-Convection Permitting Third Pole (CPTP) pilot study has suggested that the kilometer-scale modeling can resolve more orographic drag, thereby resulting in weakened northward flow over the southern TP along the Himalayas (Zhou et al. 2021).

\section{Summary and discussion}

In the present study, four simulations (GTP, GVC, MTP, and MVC) were performed to investigate the effects of two different cumulus schemes (Grell and MIT) and two landsurface hydrology schemes (TOP and VIC) on modeling the TP climate during the wet season. We evaluated their effects on the simulations of air temperature, precipitation, and surface energy-water balance. The different performances of the RegCM4 in simulating precipitation characteristics during wet seasons between different schemes were also investigated by comparing large-scale moisture transport and vertical motion.
The RegCM4 model reproduced the observed spatial pattern of air temperature pretty well, although a common cold bias existed on the western TP and a warm bias on the eastern TP. The CPS exerted a greater impact on simulated air temperature than the LSHS. The Grell and VIC schemes tended to produce warmer temperatures than the MIT and TOP schemes. The GTP simulation provided the best estimate for observed air temperature compared to the other model setups.

For precipitation, the RegCM4 reasonably simulated spatial distribution of observed precipitation, although there exist large biases, which largely rely on the choice of CPS. The MIT scheme can significantly reduce the wet bias generated by the Grell scheme, especially on the southeastern TP. The LSHS can also have some significant impacts, mainly in the hinterland of the TP, and the VIC scheme decreased the wet bias of the TOP scheme. Relatively speaking, the MVC model can give the best simulation of precipitation.

Concerning the diurnal variation of precipitation, the RegCM4 simulations largely reproduced the main spatial pattern of diurnal peak times for precipitation amount and frequency but showed a low skill for precipitation intensity. The regionally averaged diurnal cycles of precipitation amount and frequency were satisfactorily captured by the RegCM4, although there remained some differences in phase and magnitude. Relative to the GPM data, the Grell scheme tended to produce delayed peak time, but the MIT scheme advanced it. The LSHSs did not have significant effects on the phase of diurnal cycles.

Higher LSP was simulated by the Grell scheme than the MIT scheme while higher CP was simulated by the latter; the VIC scheme produced slightly lower LSP and CP than the TOP scheme. In addition, CPS significantly affected the amount of not only CP but also LSP; in general, the models with the MIT scheme reduced LSP and moderately increased $\mathrm{CP}$, simulating proportions of $\mathrm{CP}$ to total precipitation that were close to the ERA5 reference data.

The energy and water balance components were significantly influenced by the CPS and LSHS; the cascading physical processes are summarized in Fig. 15. Compared to the Grell scheme, the MIT scheme reduced the strength of the radiation components and increased soil moisture, leading to an increase in ET and a decrease in the Bowen ratio, further resulting in colder air temperatures and a weaker GHS. Compared to the TOP scheme, the VIC scheme also produced a slightly weaker GHS by means of reducing NR and soil moisture and increasing the Bowen ratio.

The GHS strength and different CPSs caused anomalous large-scale MFT to impact precipitation. With the decreased GHS, the MIT scheme substantially weakened the anomalous southwesterlies and MFC on the southeastern TP, contributing to the reduced wet biases of LSP and precipitation. The LSHS also had an influence on the large-scale 
Fig. 15 Schematic representation of possible mechanism influencing climate simulations over the TP. Effects of CPS (LSHS): the experiment with the MIT (VIC) scheme relative to that with the Grell (TOP) scheme. The flows of the effects of LSHS that don't share with those of CPS are in additional blue. NSR net shortwave radiation, $N L R$ net longwave radiation, $E T$ evapotranspiration, $M S E$ moisture static energy

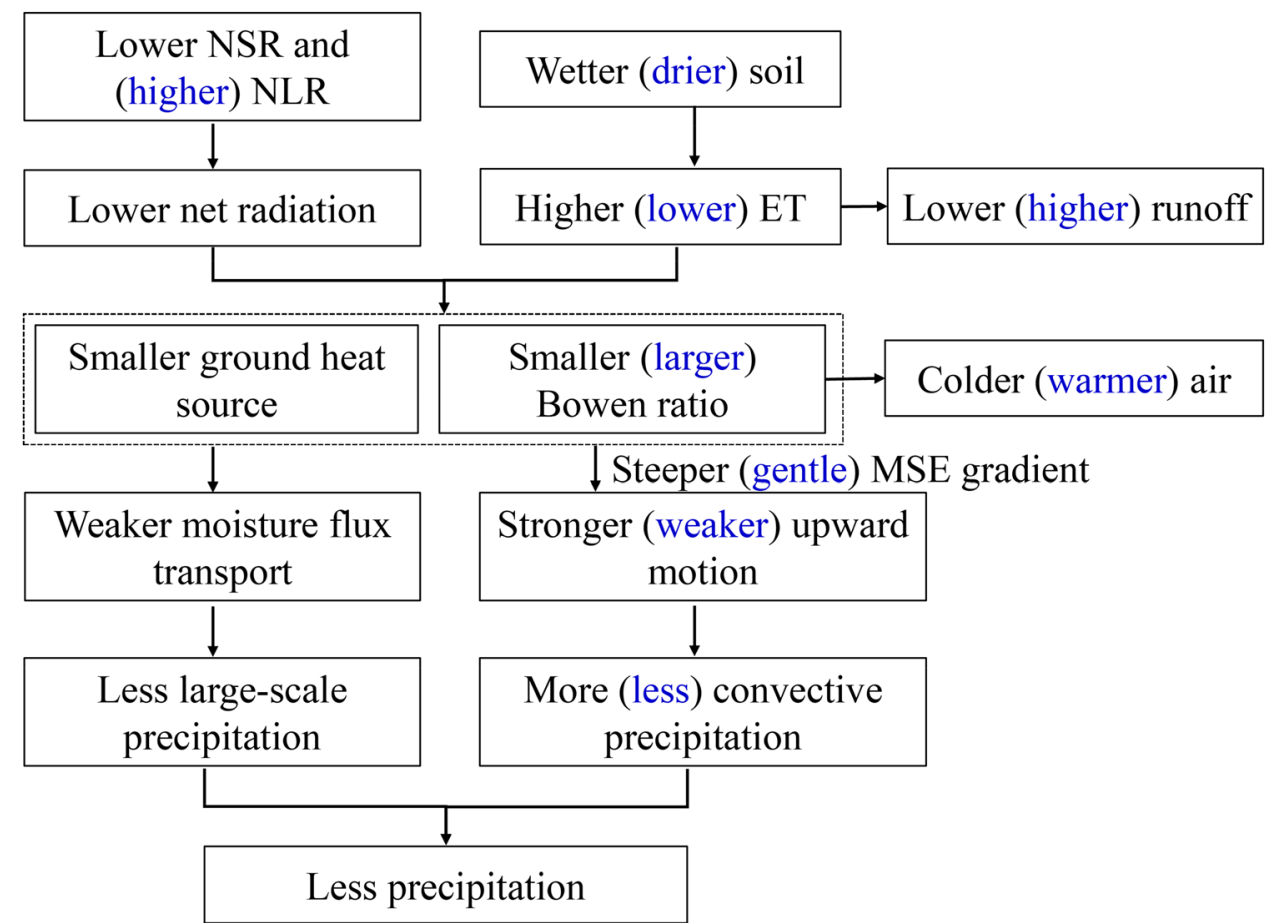

MFT, and the models with the VIC scheme slightly reduced the MFT and MFC compared to the models with the TOP scheme. The MSE analysis revealed that the high CP in the simulations with the MIT scheme could be explained by the destabilization between 600 and $300 \mathrm{hPa}$ and upward motion, mainly associated with the vertical thermal contribution, while the destabilization in the simulations with the Grell scheme was confined to the lower troposphere (below $500 \mathrm{hPa}$ ). The low $\mathrm{CP}$ in the simulations with the VIC scheme could be attributed to the inhibition of shallow convection, which was caused by the moisture contribution.

Finally, CPSs interacted with LSHSs to impact regional climate simulation over the TP. Sensitivities of climate variables to different CPSs were generally larger in the model simulations with the TOP scheme than with the VIC scheme. Regarding the choice of CPS, the VIC runoff scheme shows superior performance over the TOP runoff scheme for simulating the surface climate and energy and water balance in comparison with in-situ observation and reanalysis products. To ensure superior performance of the RegCM4 configured with the VIC scheme, the surface parameters of the VIC need to be re-calibrated using the offline CLM45-VIC and coupled model RegCM4-CLM45-VIC against in-situ observations as recommended by relevant studies (Huang and Liang 2006; Anwar et al. 2019; Anwar and Diallo 2020; Anwar 2020).

The ERA5 dataset was used as reference data to comparatively interpret the possible error sources and different performances of the RegCM4. Although the ERA5 has assimilated a large number of observations, and some variables have been validated with observational datasets on the TP (e.g., Cheng et al. 2019; Li et al. 2020; Wang et al. 2020), the reliability of the ERA5 data, especially for surface variables, remains to be assessed. Since these data are not actual measurements and there are few available and proper observations of surface variables, further validation for the model simulations especially at a fine-scale, with the aid of newly collected in-situ observations, is still needed. Convection-permitting models, which allow the generation of fine-scale simulation, often at a kilometerscale resolution, have been underway for some time (Prein et al. 2015). A dynamical downscaling simulation over a GCM may be needed prior to conducting convectionpermitting models since the highest spatial resolution of the global atmospheric forcing dataset is currently around $31 \mathrm{~km}$ (ERA5). More accurate regional atmospheric forcing through various parameterization sensitivity tests would be beneficial for conducting convection-permitting models. In addition, the LSHS indeed triggers a couple of significant changes in related physical processes, such as energy and water balances, although the effects of the LSHS on air temperature and precipitation are smaller than those of the CPS. The results revealed in this study could serve as a reference for readers in the field of hydrometeorology intent on understanding the climate effect of the hydrological cycle.

Supplementary Information The online version contains supplementary material available at https://doi.org/10.1007/s00382-021-05781-1. 
Acknowledgements The study was jointly supported by the National Key Research and Development Program of China (2019YFC0507401), the Strategic Priority Research Program of the Chinese Academy of Sciences (CAS) (XDA20100102), the Innovation Research Group of NSFC (41721091), the National Natural Science Foundation of China (41601077; 41771068), the Youth Innovation Promotion Association CAS (2018460), and the State Key Laboratory of Cryospheric Science (SKLCS-ZZ-2021). The authors also would like to acknowledge the funding from the China Scholarship Council Program (201804910129) and the Swedish STINT (CH2019-8377). This work is a contribution to the Swedish BECC and MERGE. The computations were performed on resources provided by the Swedish National Infrastructure for Computing (SNIC) at the National Supercomputer Centre in Sweden (NSC) partially funded by the Swedish Research Council through grant agreement no. 2018-05973.

Author contributions XW conceived and designed the study. XW, DC, and GP designed the experiments. XW performed the model simulations. XW, DC, GP, TO, and MY contributed to data analysis and interpretation. XW drafted the manuscript with inputs from DC, SA, and TO. All authors edited the manuscript.

Funding Open access funding provided by University of Gothenburg. The study was jointly supported by the National Key Research and Development Program of China (2019YFC0507401), the Strategic Priority Research Program of the Chinese Academy of Sciences (CAS) (XDA20100102), the Innovation Research Group of NSFC (41721091), the National Natural Science Foundation of China (41601077; 41771068), the Youth Innovation Promotion Association CAS (2018460), and the State Key Laboratory of Cryospheric Science (SKLCS-ZZ-2021). The authors also would like to acknowledge the funding from the China Scholarship Council Program (201804910129) and the Swedish STINT (CH2019-8377). This work is a contribution to the Swedish BECC and MERGE. The computations were performed on resources provided by the Swedish National Infrastructure for Computing (SNIC) at the National Supercomputer Centre in Sweden (NSC) partially funded by the Swedish Research Council through Grant Agreement No. 2018-05973.

Availability of data and material All data used in this study are freely accessible. The relevant data for running RegCM4 can be downloaded from http://clima-dods.ictp.it/data/regcm $4 /$. The $0.25^{\circ}$ gridded CN05.1 data are available by contacting the authors (Wu and Gao 2013). GPM IMERG data can be downloaded from https://gpm.nasa.gov/missions/ GPM. CERES data are accessible at https://ceres.larc.nasa.gov/data/. ERA5 data is available at https://www.ecmwf.int/en/forecasts/datasets/ browse-reanalysis-datasets. Evapotranspiration and surface soil moisture can be accessed from http://data.tpdc.ac.cn/en/.

Code availability Data processing and mapping are based on the NCL script and MATLAB program. The code used in the study is available by contacting Xuejia Wang (xjwang@lzb.ac.cn).

\section{Declarations}

Conflict of interest Authors declare no competing interests.

Consent for publication Written informed consent for publication was obtained from all participants.

Open Access This article is licensed under a Creative Commons Attribution 4.0 International License, which permits use, sharing, adaptation, distribution and reproduction in any medium or format, as long as you give appropriate credit to the original author(s) and the source, provide a link to the Creative Commons licence, and indicate if changes were made. The images or other third party material in this article are included in the article's Creative Commons licence, unless indicated otherwise in a credit line to the material. If material is not included in the article's Creative Commons licence and your intended use is not permitted by statutory regulation or exceeds the permitted use, you will need to obtain permission directly from the copyright holder. To view a copy of this licence, visit http://creativecommons.org/licenses/by/4.0/.

\section{References}

Anthes RA (1977) A cumulus parameterization scheme utilizing a onedimensional cloud model. Mon Weather Rev 105(3):270-286. https://doi.org/10.1175/1520-0493(1977)105\%3c0270:ACPSUA\%3e2.0.CO;2

Anwar SA (2020) On the contribution of dynamic leaf area index in simulating the African climate using a regional climate model (RegCM4). Theor Appl Climatol. https://doi.org/10.1007/ s00704-020-03414-x

Anwar SA, Diallo I (2020) The influence of two land-surface hydrology schemes on the terrestrial carbon cycle of Africa: a regional climate model study. Int J Climatol. https://doi.org/10.1002/joc. 6762

Anwar SA, Zakey AS, Robaa SM, Abdel Wahab MM (2019) The influence of two land-surface hydrology schemes on the regional climate of Africa using the RegCM4 model. Theor Appl Climatol 136(3):1535-1548. https://doi.org/10.1007/s00704-018-2556-8

Arakawa A (2004) The cumulus parameterization problem: past, present, and future. J Clim 17(13):2493-2525. https://doi.org/10. 1175/1520-442(2004)017\%3c2493:RATCPP\%3e2.0.CO;2

Bao Q, Li J (2020) Progress in climate modeling of precipitation over the Tibetan Plateau. Natl Sci Rev 7(3):486-487. https://doi.org/ 10.1093/nsr/nwaa006

Bao X, Zhang F (2019) How accurate are modern atmospheric reanalyses for the data-sparse Tibetan Plateau region? J Clim 32(21):7153-7172. https://doi.org/10.1175/jcli-d-18-0705.1

Beven KJ, Kirkby MJ (1979) A physically based, variable contributing area model of basin hydrology/Un modèle à base physique de zone d'appel variable de l'hydrologie du bassin versant. Hydrol Sci Bull 24(1):43-69. https://doi.org/10.1080/02626667909491834

Chai L, Liu S, Zhu Z (2020) Land surface soil moisture dataset of SMAP time-expanded daily $0.25^{\circ} \times 0.25^{\circ}$ over Qinghai-Tibet Plateau Area (SMsmapTE, V1). Natl Tibet Plateau Data Cent. https:// doi.org/10.11888/Soil.tpdc. 270948

Chen D, Xu B, Yao T, Guo Z, Cui P, Chen F, Zhang R, Zhang X, Zhang Y, Fan J (2015) Assessment of past, present and future environmental changes on the Tibetan Plateau. Chin Sci Bull 60(32):3025-3035. https://doi.org/10.1360/N972014-01370

Chen D, Tian Y, Yao T, Ou T (2016) Satellite measurements reveal strong anisotropy in spatial coherence of climate variations over the Tibet Plateau. Sci Rep 6(1):30304. https://doi.org/10.1038/ srep30304

Cheng M, Zhong L, Ma Y, Zou M, Ge N, Wang X, Hu Y (2019) A study on the assessment of multi-source satellite soil moisture products and reanalysis data for the Tibetan Plateau. Remote Sens 11(10):1196. https://doi.org/10.3390/rs11101196

Dee DP, Uppala SM, Simmons AJ, Berrisford P, Poli P, Kobayashi S et al (2011) The ERA-Interim reanalysis: configuration and performance of the data assimilation system. Q J R Meteorol Soc 137(656):553-597. https://doi.org/10.1002/qj.828 
Dirmeyer PA, Jin Y, Singh B, Yan X (2013) Trends in land-atmosphere interactions from CMIP5 simulations. J Hydrometeorol 14(3):829-849. https://doi.org/10.1175/JHM-D-12-0107.1

Duan A, Wu G, Liu Y, Ma Y, Zhao P (2012) Weather and climate effects of the Tibetan Plateau. Adv Atmos Sci 29(5):978-992. https://doi.org/10.1007/s00376-012-1220-y

Emanuel KA (1991) A scheme for representing cumulus convection in large-scale models. J Atmos Sci 48(21):2313-2329. https:// doi.org/10.1175/1520-0469(1991)048\%3c2313:ASFRCC\%3e2.0. $\mathrm{CO} ; 2$

Emanuel KA, Živković-Rothman M (1999) Development and evaluation of a convection scheme for use in climate models. J Atmos Sci 56(11):1766-1782. https://doi.org/10.1175/1520-0469(1999) 056\%3c1766:DAEOAC\%3e2.0.CO;2

Feng L, Zhou T (2012) Water vapor transport for summer precipitation over the Tibetan Plateau: multidata set analysis. J Geophys Res Atmos. https://doi.org/10.1029/2011JD017012

Fu Y, Ma Y, Zhong L, Yang Y, Guo X, Wang C, Xu X, Yang K, Xu X, Liu L, Fan G, Li Y, Wang D (2020) Land-surface processes and summer-cloud-precipitation characteristics in the Tibetan Plateau and their effects on downstream weather: a review and perspective. Natl Sci Rev 7(3):500-515. https://doi.org/10.1093/ nsr/nwz226

Gao Y, Chen D (2017) Modeling of regional climate over the Tibetan Plateau. Oxford University Press

Gao X, Shi Y, Filippo G (2011) A high resolution simulation of climate change over China. Sci China Earth Sci 54(1674-7313):462. https://doi.org/10.1007/s11430-010-4035-7

Gao X, Shi Y, Giorgi F (2016) Comparison of convective parameterizations in RegCM4 experiments over China with CLM as the land surface model. Atmos Ocean Sci Let 9(4):246-254. https://doi. org/10.1080/16742834.2016.1172938

Gao Y, Xiao L, Chen D, Chen F, Xu J, Xu Y (2017a) Quantification of the relative role of land-surface processes and large-scale forcing in dynamic downscaling over the Tibetan Plateau. Clim Dyn 48(5-6):1705-1721. https://doi.org/10.1007/s00382-016-3168-6

Gao Y, Leung LR, Zhao C, Hagos S (2017b) Sensitivity of US summer precipitation to model resolution and convective parameterizations across gray zone resolutions. J Geophys Res Atmos 122(5):2714-2733. https://doi.org/10.1002/2016jd025896

Ghosh KG (2018) Analysis of rainfall trends and its spatial patterns during the last century over the gangetic West Bengal, Eastern India. J Geovis Spat Anal 2(2):15. https://doi.org/10.1007/ s41651-018-0022-x

Giorgi F (2019) Thirty years of regional climate modeling: where are we and where are we going next? J Geophys Res Atmos 124(11):5696-5723. https://doi.org/10.1029/2018jd030094

Giorgi F, Bi X, Pal JS (2004) Mean, interannual variability and trends in a regional climate change experiment over Europe. I. Presentday climate (1961-1990). Clim Dyn 22(6):733-756

Giorgi F, Coppola E, Solmon F, Mariotti L, Sylla MB, Bi X, Elguindi N, Diro GT, Nair V, Giuliani G (2012) RegCM4: model description and preliminary tests over multiple CORDEX domains. Clim Res 52:7-29. https://doi.org/10.3354/cr01018

Giorgi F, Torma C, Coppola E, Ban N, Schär C, Somot S (2016) Enhanced summer convective rainfall at Alpine high elevations in response to climate warming. Nat Geosci 9(8):584-589. https:// doi.org/10.1038/ngeo2761

Grell GA (1993) Prognostic evaluation of assumptions used by cumulus parameterizations. Mon Weather Rev 121(3):764-787. https:// doi.org/10.1175/1520-0493(1993)121\%3c0764:PEOAUB\%3e2.0. $\mathrm{CO} ; 2$

Gu H, Yu Z, Peltier WR, Wang X (2020) Sensitivity studies and comprehensive evaluation of RegCM4.6.1 high-resolution climate simulations over the Tibetan Plateau. Clim Dyn 54:3781. https:// doi.org/10.1007/s00382-020-05205-6
Gutowski WJ Jr, Ullrich PA, Hall A, Leung LR, O'Brien TA, Patricola CM, Arritt RW, Bukovsky MS, Calvin KV, Feng Z, Jones AD, Kooperman GJ, Monier E, Pritchard MS, Pryor SC, Qian Y, Rhoades AM, Roberts AF, Sakaguchi K, Urban N, Zarzycki C (2020) The ongoing need for high-resolution regional climate models: Process understanding and stakeholder information. Bull Am Meteorol Soc 101(5):E664-E683. https://doi.org/10.1175/ bams-d-19-0113.1

Han C, Ma Y, Chen X, Ma W, Wang B, Zhong L, Su Z (2020) Monthly mean evapotranspiration data set of the Tibet Plateau (20012018). Natl Tibet Plateau Data Cent. https://doi.org/10.11888/ Hydro.tpdc. 270995

Hersbach H, de Rosnay P, Bell B, Schepers D, Simmons A, Soci C, Abdalla S, Alonso-Balmaseda M, Balsamo G, Bechtold P (2018) Operational global reanalysis: progress, future directions and synergies with NWP, ECMWF ERA report series, N27

Hersbach H, Bell B, Berrisford P, Hirahara S, Horányi A, MuñozSabater J et al (2020) The ERA5 global reanalysis. Q J R Meteorol Soc 146(730):1999-2049. https://doi.org/10.1002/qj.3803

Holtslag AAM, Boville BA (1993) Local versus nonlocal boundarylayer diffusion in a global climate model. J Clim 6(10):18251842. https://doi.org/10.1175/1520-0442(1993)006\%3c1825: LVNBLD\%3e2.0.CO;2

Hou AY, Kakar RK, Neeck S, Azarbarzin AA, Kummerow CD, Kojima M, Oki R, Nakamura K, Iguchi T (2014) The global precipitation measurement mission. Bull Am Meteorol Soc 95(5):701-722. https://doi.org/10.1175/bams-d-13-00164.1

Huang M, Liang X (2006) On the assessment of the impact of reducing parameters and identification of parameter uncertainties for a hydrologic model with applications to ungauged basins. J Hydrol 320(1):37-61. https://doi.org/10.1016/j.jhydrol.2005. 07.010

Huffman GJ, Bolvin DT, Nelkin EJ, Tan J (2020) Integrated MultisatellitE Retrievals for GPM (IMERG) technical documentation. NASA/GSFC Code 612(47):83

Immerzeel WW, van Beek LPH, Bierkens MFP (2010) Climate change will affect the Asian water towers. Science 328(5984):1382-1385. https://doi.org/10.1126/science. 1183188

Immerzeel WW, Lutz AF, Andrade M, Bahl A, Biemans H, Bolch T et al (2020) Importance and vulnerability of the world's water towers. Nature 577(7790):364-369. https://doi.org/10.1038/ s41586-019-1822-y

Kain JS, Fritsch JM (1993) Convective parameterization for mesoscale models: the Kain-Fritsch scheme. In: Emanuel KA, Raymond DJ (eds) The representation of cumulus convection in numerical models. American Meteorological Society, Boston, pp 165-170. https://doi.org/10.1007/978-1-935704-13-3_16

Kato S, Rose FG, Rutan DA, Thorsen TJ, Loeb NG, Doelling DR, Huang X, Smith WL, Su W, Ham SH (2018) Surface irradiances of edition 4.0 clouds and the Earth's Radiant Energy System (CERES) Energy Balanced and Filled (EBAF) Data Product. J Clim 31(11):4501-4527. https://doi.org/10.1175/jcli-d-17-0523.1

Kiehl JT, Hack JJ, Bonan GB, Boville BA, Breigleb BP, Williamson D, Rasch P (1996) Description of the NCAR community climate model (CCM3). National Center for Atmospheric Research

Kukulies J, Chen D, Wang M (2020) Temporal and spatial variations of convection, clouds and precipitation over the Tibetan Plateau from recent satellite observations. Part II: precipitation climatology derived from global precipitation measurement mission. Int J Climatol 40(11):4858-4875. https://doi.org/10.1002/joc.649

Kummerow C, Hong Y, Olson WS, Yang S, Adler RF, McCollum J, Ferraro R, Petty G, Shin D-B, Wilheit TT (2001) The evolution of the goddard profiling algorithm (GPROF) for rainfall estimation from passive microwave sensors. J Appl Meteorol Climatol 40(11):1801-1820. https://doi.org/10.1175/1520-0450(2001) 040\%3c1801:teotgp\%3e2.0.co;2 
Kushwaha AP, Pandey AC, Mahto SS (2018) Assessment of runoff pattern and relationship to sediment yield of Bhagirathi-Alaknanda River Basin using geospatial techniques. J Geovis Spat Anal 2(2):9. https://doi.org/10.1007/s41651-018-0016-8

Leung LR, Kuo Y-H, Tribbia J (2006) Research needs and directions of regional climate modeling Using WRF and CCSM. Bull Am Meteorol Soc 87(12):1747-1751. https://www.jstor.org/stable/ 26217238

Li H, Huang M, Wigmosta MS, Ke Y, Coleman AM, Leung LR, Wang A, Ricciuto DM (2011) Evaluating runoff simulations from the Community Land Model 4.0 using observations from flux towers and a mountainous watershed. J Geophys Res Atmos. https://doi. org/10.1029/2011jd016276

Li X, Wang L, Chen D, Yang K, Xue B, Sun L (2013) Near-surface air temperature lapse rates in the mainland China during 1962-2011. J Geophys Res Atmos 118(14):7505-7515. https://doi.org/10. 1002/jgrd.50553

Li D, Yang K, Tang W, Li X, Zhou X, Guo D (2020) Characterizing precipitation in high altitudes of the western Tibetan plateau with a focus on major glacier areas. Int J Climatol. https://doi.org/10. 1002/joc. 6509

Liang X, Lettenmaier DP, Wood EF, Burges SJ (1994) A simple hydrologically based model of land surface water and energy fluxes for general circulation models. J Geophys Res Atmos 99(D7):14415-14428. https://doi.org/10.1029/94jd00483

Lin C, Chen D, Yang K, Ou T (2018) Impact of model resolution on simulating the water vapor transport through the central Himalayas: implication for models' wet bias over the Tibetan Plateau. Clim Dyn 51(9):3195-3207. https://doi.org/10.1007/ s00382-018-4074-x

Loeb NG, Doelling DR, Wang H, Su W, Nguyen C, Corbett JG, Liang L, Mitrescu C, Rose FG, Kato S (2018) Clouds and the earth's radiant energy system (CERES) energy balanced and filled (EBAF) top-of-atmosphere (TOA) edition-4.0 data product. J Clim 31(2):895-918. https://doi.org/10.1175/jcli-d-17-0208.1

Ma Y, Tang G, Long D, Yong B, Zhong L, Wan W, Hong Y (2016) Similarity and error intercomparison of the GPM and its predecessor-TRMM multisatellite precipitation analysis using the best available hourly gauge network over the Tibetan Plateau. Remote Sens 8(7):569. https://doi.org/10.3390/rs8070569

Ma Q, Li Y, Feng H, Yu Q, Zou Y, Liu F, Pulatov B (2021) Performance evaluation and correction of precipitation data using the 20-year IMERG and TMPA precipitation products in diverse subregions of China. Atmos Res 249:105304. https://doi.org/ 10.1016/j.atmosres.2020.105304

Maussion F, Scherer D, Mölg T, Collier E, Curio J, Finkelnburg R (2014) Precipitation seasonality and variability over the Tibetan Plateau as resolved by the High Asia Reanalysis. J Clim 27(5):1910-1927. https://doi.org/10.1175/jcli-d-13-00282.1

Ménégoz M, Gallée H, Jacobi HW (2013) Precipitation and snow cover in the Himalaya: from reanalysis to regional climate simulations. Hydrol Earth Syst Sci 17(10):3921-3936. https://doi. org/10.5194/hess-17-3921-2013

Mlawer EJ, Taubman SJ, Brown PD, Iacono MJ, Clough SA (1997) Radiative transfer for inhomogeneous atmospheres: RRTM, a validated correlated-k model for the longwave. J Geophys Res Atmos 102(D14):16663-16682. https://doi.org/10.1029/97jd0 0237

Neupane N, Cook KH (2013) A nonlinear response of Sahel rainfall to Atlantic warming. J Clim 26(18):7080-7096. https://doi.org/10. 1175/JCLI-D-12-00475.1

Niu GY, Yang ZL (2006) Effects of frozen soil on snowmelt runoff and soil water storage at a continental scale. J Hydrometeorol 7(5):937-952. https://doi.org/10.1175/jhm538.1

Niu GY, Yang ZL, Dickinson RE, Gulden LE (2005) A simple TOPMODEL-based runoff parameterization (SIMTOP) for use in global climate models. J Geophys Res Atmos 110:D21106. https:// doi.org/10.1029/2005JD006111

Niu X, Tang J, Wang S, Fu C, Chen D (2020) On the sensitivity of seasonal and diurnal precipitation to cumulus parameterization over CORDEX-EA-II. Clim Dyn 54(1-2):373-393

Oleson KW, Niu G-Y, Yang Z-L, Lawrence DM, Thornton PE, Lawrence PJ, Stöckli R, Dickinson RE, Bonan GB, Levis S, Dai A, Qian T (2008) Improvements to the community land model and their impact on the hydrological cycle. J Geophys Res Biogeosci. https://doi.org/10.1029/2007jg000563

Oleson K, Lawrence D, Bonan G, Drewniak B, Huang M, Koven C, Levis S, Li F, Riley W, Subin Z (2013) Technical Description of version 4.5 of the Community Land Model (CLM) (NCAR Technical Note No. NCAR/TN-503+ STR). Citeseer. National Center for Atmospheric Research, PO Box 3000

Ou T, Chen D, Chen X, Lin C, Yang K, Lai H-W, Zhang F (2020) Simulation of summer precipitation diurnal cycles over the Tibetan Plateau at the gray-zone grid spacing for cumulus parameterization. Clim Dyn 54(7):3525-3539. https://doi.org/10.1007/ s00382-020-05181-x

Pal JS, Small EE, Eltahir EAB (2000) Simulation of regional-scale water and energy budgets: representation of subgrid cloud and precipitation processes within RegCM. J Geophys Res Atmos 105(D24):29579-29594. https://doi.org/10.1029/2000jd900415

Prein AF, Langhans W, Fosser G, Ferrone A, Ban N, Goergen K, Keller M, Tölle M, Gutjahr O, Feser F, Brisson E, Kollet S, Schmidli J, van Lipzig NPM, Leung R (2015) A review on regional convection-permitting climate modeling: demonstrations, prospects, and challenges. Rev Geophys 53(2):323-361. https://doi.org/10.1002/ 2014rg000475

Pu B, Cook KH (2012) Role of the West African Westerly Jet in Sahel rainfall variations. J Clim 25(8):2880-2896. https://doi.org/10. 1175/jcli-d-11-00394.1

Qu Y, Zhu Z, Chai L, Liu S, Montzka C, Liu J, Yang X, Lu Z, Jin R, Li X, Guo Z, Zheng J (2019) Rebuilding a microwave soil moisture product using random forest adopting AMSR-E/AMSR2 brightness temperature and SMAP over the Qinghai-Tibet Plateau China. Remote Sens 11(6):683. https://doi.org/10.3390/rs110 60683

Reynolds RW, Rayner NA, Smith TM, Stokes DC, Wang W (2002) An improved in situ and satellite SST analysis for climate. J Clim 15(13):1609-1625. https://doi.org/10.1175/1520-0442(2002) 015\%3c1609:AIISAS\%3e2.0.CO;2

Saini R, Wang G, Yu M, Kim J (2015) Comparison of RCM and GCM projections of boreal summer precipitation over Africa. J Geophys Res Atmos 120(9):3679-3699. https://doi.org/10.1002/2014J D022599

Sugimoto S, Ueno K (2010) Formation of mesoscale convective systems over the eastern Tibetan Plateau affected by plateau-scale heating contrasts. J Geophys Res Atmos. https://doi.org/10.1029/ 2009JD013609

Tang G, Ma Y, Long D, Zhong L, Hong Y (2016) Evaluation of GPM Day-1 IMERG and TMPA version-7 legacy products over Mainland China at multiple spatiotemporal scales. J Hydrol 533:152167. https://doi.org/10.1016/j.jhydrol.2015.12.008

Tang J, Wang S, Niu X, Hui P, Zong P, Wang X (2017) Impact of spectral nudging on regional climate simulation over CORDEX East Asia using WRF. Clim Dyn 48(7):2339-2357. https://doi.org/10. 1007/s00382-016-3208-2

Tiedtke M (1989) A comprehensive mass flux scheme for cumulus parameterization in large-scale models. Mon Weather Rev 117(8):1779-1800. https://doi.org/10.1175/1520-0493(1989) 117\%3c1779:ACMFSF\%3e2.0.CO;2

Wang A, Li KY, Lettenmaier DP (2008) Integration of the variable infiltration capacity model soil hydrology scheme into the 
community land model. J Geophys Res Atmos. https://doi.org/ 10.1029/2007jd009246

Wang X, Yang M, Wan G, Chen X, Pang G (2013) Qinghai-Xizang (Tibetan) Plateau climate simulation using the regional climate model RegCM3. Clim Res 57(3):173-186. https://doi.org/10. 3354/cr01167

Wang X, Yang M, Pang G (2014) Sensitivity of regional climate simulations to land-surface schemes on the Tibetan Plateau. Clim Res 62(1):25-43. https://doi.org/10.3354/cr01262

Wang X, Pang G, Yang M, Wan G (2016) Effects of modified soil water-heat physics on RegCM4 simulations of climate over the Tibetan Plateau. J Geophys Res Atmos. https://doi.org/10.1002/ 2015JD024407

Wang X, Pang G, Yang M, Zhao G (2017) Evaluation of climate on the Tibetan Plateau using ERA-Interim reanalysis and gridded observations during the period 1979-2012. Quat Int 444:76-86. https://doi.org/10.1016/j.quaint.2016.12.041

Wang X, Pang G, Yang M (2018) Precipitation over the Tibetan Plateau during recent decades: a review based on observations and simulations. Int J Climatol 38(3):1116-1131. https://doi.org/10. 1002/joc.5246

Wang X, Chen D, Pang G, Ou T, Yang M, Wang M (2020) A climatology of surface-air temperature difference over the Tibetan Plateau: results from multi-source reanalyses. Int J Climatol 40:6080-6094. https://doi.org/10.1002/joc.6568

Wang X, Chen D, Pang G, Gou X, Yang M (2021) Historical and future climates over the upper and middle reaches of the Yellow River Basin simulated by a regional climate model in CORDEX. Clim Dyn. https://doi.org/10.1007/s00382-020-05617-4

Wu J, Gao X (2013) A gridded daily observation dataset over China and comparison with the other dataset. Chin J Geophys 56(04):1102-1111. https://doi.org/10.6038/cjg20130406 (In Chinese with English abstract)

Wu G, Duan A, Liu Y, Mao J, Ren R, Bao Q, He B, Liu B, Hu W (2015) Tibetan Plateau Clim Dyn: recent research progress and outlook. Natl Sci Rev 2(1):100-116. https://doi.org/10.1093/nsr/ nwu045

Xu R, Tian F, Yang L, Hu H, Lu H, Hou A (2017) Ground validation of GPM IMERG and TRMM 3B42V7 rainfall products over southern Tibetan Plateau based on a high-density rain gauge network. J Geophys Res Atmos 122(2):910-924. https://doi.org/10.1002/ 2016JD025418
Yang K, Koike T, Fujii H, Tamura T, Xu X, Bian L, Zhou M (2004) The Daytime Evolution of the Atmospheric Boundary Layer and Convection over the Tibetan Plateau: Observations and Simulations. J Meteor Soc Japan 82(6):1777-1792. https://doi.org/10. 2151/jmsj.82.1777

Yang M, Wang X, Pang G, Wan G, Liu Z (2019) The Tibetan Plateau cryosphere: observations and model simulations for current status and recent changes. Earth Sci Rev 190:353-369. https://doi.org/ 10.1016/j.earscirev.2018.12.018

Yao T, Xue Y, Chen D, Chen F, Thompson L, Cui P, Koike T, Lau WKM, Lettenmaier D et al (2018) Recent Third Pole's rapid warming accompanies cryospheric melt and water cycle intensification and interactions between monsoon and environment: multidisciplinary approach with observations, modeling, and analysis. Bull Am Meteorol Soc 100(3):423-444. https://doi.org/ 10.1175/BAMS-D-17-0057

Ye D, Gao Y (1979) Tibetan Plateau meteorology. Science Press, Beijing (In Chinese)

You Q, Min J, Zhang W, Pepin N, Kang S (2015) Comparison of multiple datasets with gridded precipitation observations over the Tibetan Plateau. Clim Dyn 45(3):791-806. https://doi.org/10. 1007/s00382-014-2310-6

Zhang C, Tang Q, Chen D (2017) Recent changes in the moisture source of precipitation over the Tibetan Plateau. J Clim 30(5):1807-1819. https://doi.org/10.1175/jcli-d-15-0842.1

Zhou C, Zhao P, Chen J (2019) The interdecadal change of summer water vapor over the Tibetan Plateau and associated mechanisms. J Clim 32(13):4103-4119. https://doi.org/10.1175/jcli-d-18-0364.1

Zhou X, Yang K, Ouyang L, Wang Y, Jiang Y, Li X, Chen D, Prein A (2021) Added value of kilometer-scale modeling over the third pole region: a CORDEX-CPTP pilot study. Clim Dyn. https://doi. org/10.1007/s00382-021-05653-8

Zou L, Qian Y, Zhou T, Yang B (2014) Parameter tuning and calibration of RegCM3 with MIT-Emanuel cumulus parameterization scheme over CORDEX East Asia domain. J Clim 27(20):76877701. https://doi.org/10.1175/JCLI-D-14-00229.1

Publisher's Note Springer Nature remains neutral with regard to jurisdictional claims in published maps and institutional affiliations. 